\title{
The Moon: An Archive of Small Body Migration in the Solar System
}

\author{
Katherine H. Joy ${ }^{1}$ (D) Ian A. Crawford ${ }^{2} \cdot$ Natalie M. Curran $^{1}$ • \\ Michael Zolensky ${ }^{3,4}$ Amy F. Fagan ${ }^{5}$ David A. Kring ${ }^{3}$
}

Received: 20 May 2016/Accepted: 21 September 2016/Published online: 19 October 2016

(C) The Author(s) 2016. This article is published with open access at Springerlink.com

\begin{abstract}
The Moon is an archive of impact cratering in the Solar System throughout the past 4.5 billion years. It preserves this record better than larger, more complex planets like the Earth, Mars and Venus, which have largely lost their ancient crusts through geological reprocessing and hydrospheric/atmospheric weathering. Identifying the parent bodies of impactors (i.e. asteroid bodies, comets from the Kuiper belt or the Oort Cloud) provides geochemical and chronological constraints for models of Solar System dynamics, helping to better inform our wider understanding of the evolution of the Solar System and the transfer of small bodies between planets. In this review article, we discuss the evidence for populations of impactors delivered to the Moon at different times in the past. We also propose approaches to the identification and characterisation of meteoritic material on the Moon in the context of future lunar exploration efforts.
\end{abstract}

Keywords Moon · Regolith · Meteorites · Meteorite-survivability · Impact-bombardment · Lunar exploration

Katherine H. Joy

katherine.joy@manchester.ac.uk

1 School of Earth and Environmental Sciences, University of Manchester, Williamson Building, Oxford Road, Manchester M13 9PL, UK

2 Department of Earth and Planetary Sciences, Birkbeck College, University of London, Malet Street, London WC1E 7HX, UK

3 Center for Lunar Science and Exploration, The Lunar and Planetary Institute - USRA, 3600 Bay Area Blvd., Houston, TX 77058, USA

4 ARES, NASA Johnson Space Center, Houston, TX 77058, USA

5 Geosciences and Natural Resources Department, 331 Stillwell Building, Western Carolina University, Cullowhee, NC 28723, USA 


\section{Background}

Impact bombardment is a fundamental and ubiquitous Solar System process, involving the collision of planetary bodies such as asteroids, icy bodies, and other interplanetary debris. Scars of past impacts can be found on all planetary bodies and at all scales-from huge basins hundreds of $\mathrm{km}$ in diameter (e.g. the $\sim 2400 \mathrm{~km}$ South Pole-Aitken basin on the Moon; Neumann et al. 2005) to those on a microscopic scale (e.g. micron scale craters found on individual lunar glass beads: see Fig. 7.8 of McKay et al. 1991). The number, size, shape and products of these scars provide us with information about ages of planetary surfaces, the structure and stability of planetary crusts (e.g. their thickness, thermal history, and brittle/ductile nature) and the nature of the impactors that created them.

Constraining the temporal flux of impactor delivery helps to address key questions about the timing of impact bombardment in the inner Solar System (e.g. Hartmann et al. 2000; NRC 2007; Norman 2009; Morbidelli et al. 2012). Knowledge of the lunar impact record comes from both (1) surface morphology and geophysical information derived from remote sensing missions (e.g. the number, size, and superposition relationships of basins and craters; Wilhelms et al. 1987; Stöffler et al. 2006; Frey 2011; Fassett et al. 2012; Neumann et al. 2015); and (2) the lunar sample collection, which provides evidence of (1) timing of impact events from the isotopic isotopic resetting of rocks and impact melt crystallisation events (e.g. Turner et al. 1973; Tera et al. 1974; Turner 1979; Dalrymple and Ryder 1993, 1996; Cohen et al. 2000; Norman et al. 2006; Fernandes et al. 2013; FischerGödde and Becker 2012; Norman and Nemchin 2014), and (2) the type of bodies impacting the lunar surface (e.g. Joy et al. 2012; Walker et al. 2015 and references cited therein).

The lunar impact record itself is often controversial with several different models of past impact bombardment (Hartman et al. 2000; NRC 2007; Norman 2009). It is generally agreed that after the Moon's formation at $\sim 4.5 \mathrm{Ga}$, collision rates were immediately high, in an interval when leftover protoplanetary disc material and planetary embryos were being depleted through collision and inwards migration towards the Sun. This early period of bombardment is often referred to as late accretion, where several large bodies may have collided with the Moon (Day and Walker 2015; Barnes et al. 2016), adding their chemical constituents to the still hot ductile lunar magma ocean.

After crust formation was complete (see Pernet-Fisher and Joy 2015 for a recent overview) it produced a lid that likely inhibited the addition of further material to the lunar mantle. Impact events post-crust formation were lithostatically supported, leaving scars of impact basins (defined on the basis of geophysical measurements as impact craters that are $>200 \mathrm{~km}$ in diameter; Neumann et al. 2015) and smaller impact craters across the lunar surface. The duration and magnitude of basin-formation is not well known, although must have ceased by $\sim 3.8 \mathrm{Ga}$ when the most recent lunar basin, Orientale, was formed (Stöffler et al. 2006). Impact flux hypotheses vary from a continual decline in a primordial impactor rate (Hartmann 1970; Neukum et al. 2001), to an enhanced late bombardment. In the latter scenario, ideas range from a sudden spike that occurred between $\sim 3.9$ and $3.8 \mathrm{Ga}$ (often known as the lunar cataclysm; Turner et al. 1973; Tera et al. 1974; Ryder 1990; Cohen et al. 2000), to a longer period of less intense bombardment lasting from $\sim 4.2$ to $3.8 \mathrm{Ga}$ (Turner 1979; Morbidelli et al. 2012). The timing and scale of these events is being tested with renewed sample analysis using a wide range of isotopic techniques, and will greatly benefit from future sample return mission opportunities to key stratigraphic marker basin sites (NRC 2007). 
Petrological, geochemical, isotopic, and geologic data provides evidence for the parentbodies of such basin-forming impactors (e.g. Kring and Cohen 2002 and references therein; Strom et al. 2005; Puchtel et al. 2008; Joy et al. 2012; Marchi et al. 2012; Sharp et al. 2014; Liu et al. 2015; Walker et al. 2015), and provides critical constraints to models of the Solar System's dynamical environment. A wide variety of these theoretical models have emerged since the early proposals of Wetherill (1975), and these are constantly being developed and refined as new lunar samples and geological data becomes available. Some ideas invoke galactic scale processes such as disruption of the Oort Cloud or Kuiper belt by a wandering star (e.g. Mamajek et al. 2015), supernova events (e.g. Trieloff 2015; Binns et al. 2016; Breitschwerdt et al. 2016; Wallner et al. 2016), and gravitational perturbations associated with the Solar System crossing the galactic plane (e.g. Rampino 2015). Alternatively, Solar System-specific causes may have been responsible, such as the catastrophic disruption of a large asteroid or early planetary body (Ćuk et al. 2010; Ćuk 2012). A recent set of theories (collectively known as the 'Nice Model') invokes the disruption of the main asteroid belt (Minton and Malhotra 2009, 2010) or the Kuiper belt (Koeberl 2003 and references therein; Jørgensen et al. 2009), or some combination of the two regions (Tsiganis et al. 2005), when outer Solar System gas giant planets entered mean resonance orbits causing them to migrate (Tsiganis et al. 2005; Morbidelli et al. 2005, 2012; Gomes et al. 2005; Bottke et al. 2007; Levison et al. 2009).

Constraining this record on the Moon is vital to understanding Earth's early history, as the Earth and Moon will have been subjected to bombardment by the same population of impactors. However, the Earth has largely erased evidence of its early impact history. It is recognised that Earth probably experienced a heavier and longer bombardment than the Moon as a consequence of its greater size and gravitational focusing effects (Bottke et al. 2012), but the lunar record still remains central to constraining models of Earth's impact history (NRC 2007).

Impact bombardment after $3.5 \mathrm{Ga}$ declined considerably, although smaller impact craters pockmark geological units throughout the Eratosthenian and Copernican eras. Such records are also preserved on Earth through the Archean, Protoerozoic and Phanerozoic eras witnessed by the occurrence of impact spherule beds (Johnson and Melosh 2012) and large impact structures, such as Vredefort, Sudbury, and Chicxulub. Such impact spikes may have had considerable effects on the biologic evolution and development of our planet (e.g. Walker et al. 1983; Ryder et al. 2000; Kring 2003; Ryder 2003).

Bombardment of the Earth-Moon system continues to the present day. For example, evidence for recent crater forming events on Earth include the $1 \mathrm{~km}$ diameter Barringer Crater $\sim 50,000$ years ago, the multiple small $(10 \mathrm{~s}$ to $183 \mathrm{~m})$ impact craters at Henbury formed 4200 years ago (Storzer and Wagner 1977), and the $45 \mathrm{~m}$ diameter Kamil Crater at $<5000$ years ago (Folco et al. 2011): all these were formed by iron asteroid impactors. In the last two centuries significant meteor airblast (fireball) events on Earth like Tunguska in 1908 and Chelyabinsk in 2013 have been reported, and impact cratering events have also been witnessed on the Moon. These lunar events were recorded by the Apollo seismic stations (Oberst and Nakamura 1991; Gudkova et al. 2011), observations of impact flashes from Earth-based monitoring programmes (Oberst et al. 2012; Suggs et al. 2014) and identification of newly formed impact craters in high-resolution lunar images (Suggs et al. 2014; Robinson et al. 2015). These studies have suggested that all very recent impactors to the Earth-Moon system are associated with small (i.e., a few meters wide) $100 \mathrm{~s}$ of $\mathrm{g}$ to $10 \mathrm{~s}$ of $\mathrm{kg}$ mass impactors that produce craters in the $10 \mathrm{~s}$ of m diameter size range (Oberst et al. 2012; Suggs et al. 2014). 


\section{Evidence of Small Body Impactors}

To fully understand the causes of impact spikes in the Earth-Moon system it is clearly important to determine the source of projectiles. Here we distinguish between impacts that occurred during the final stages of lunar accretion, and those that occurred after accretion was substantially complete.

\subsection{Late Accretion}

After the Moon's formation, in a time window often referred to as the late accretion, or sometimes as the late veneer, the 'primitive' lunar mantle was modified by the addition of projectiles (Day et al. 2012). The time interval has traditionally been defined as between lunar core segregation (determined by highly siderophile elements (HSE) partitioning into the lunar core; Dale et al. 2012; Day et al. 2016; Day and Walker 2015; Kruijer et al. 2015) and the end of magma ocean solidification (which marks the point when the crust inhibited the addition of significant quantities of further exogenous material to the mantle). The time interval was dependent on the cooling rate of the Moon and is thought, on the basis of lunar sample ages, to have lasted until $\sim 200 \mathrm{Myr}$ after lunar formation (Elkins-Tanton et al. 2011).

This late accretion interval marks a period of chemical modification of the Moon's interior when impactors were chemically mixed into an initially hot and convecting, and later cooling, lunar magma ocean. The amount of material accreted was dependent on the size and number of projectiles derived from leftover planetesimal populations, and may represent just a few very large mass impact events (Bottke et al. 2010). Such impactors cannot have altered the Moon's oxygen isotope budget extensively enough for it to be different from the Earth-Moon starting composition (Young et al. 2016). The quantity and types of impactors (e.g., Brandon et al. 2005; Walker et al. 2015), and the effectiveness of chemical mixing in the magma ocean and possible prolonged core elemental sequestration (e.g., Rubie et al. 2016) is under debate. However, osmium isotopes and HSE signatures of mantle partial melts (i.e., mare basalt samples) suggest that $\sim 0.02 \mathrm{wt} \%$ of the Moon's mass could have been added in this interval from primitive (i.e. chondritic) asteroid sourced impactors (Day and Walker 2015). These impactors could also have contributed to the Moon's volatile and moderately volatile element budget and isotopic signature (McCubbin et al. 2015; Tartèse 2016) (although degassing of the magma ocean may have contributed to some later depletion of volatile species Boyce et al. 2015; Kato et al. 2015). Examination of the lunar rock hydrogen and nitrogen isotope records indicate that the sources of impactors that delivered such volatiles to the lunar magma ocean were dominated by water or ice-rich carbonaceous chondrite-like asteroid projectiles (Barnes et al. 2016).

\subsection{Post-late Accretion Impactors}

Impactors striking the lunar surface after crust formation, and the closure of the lunar magma ocean, represent a continuous crustal accretion phase of bombardment. This time window includes the period of a high impact flux before $3.8 \mathrm{Ga}$ (the window of basin formation), and a post-basin-formation declining rate of projectile delivery and crater formation. Locating and analysing such impactors in order to chemically and isotopically 
identify their parent bodies should be a high priority science activity for future lunar regolith research and exploration efforts.

\subsubsection{Indirect Evidence}

Chemical signatures of material accreting to the lunar crust have been identified from budgets of HSEs and volatile elements in lunar impact rocks and soils.

HSE analyses of individual lunar basin and crater impact melt breccias of known age imply that projectile compositions in the basin-forming epoch were similar to both primitive asteroids (i.e. ordinary and carbonaceous chondrites) and also differentiated asteroids (i.e. iron meteorites derived from planetary embryo cores (Kring and Cohen 2002; Norman et al. 2006; Fischer-Gödde and Becker 2012; Walker et al. 2015). Although HSE contents and relative isotope abundances have not yet been determined for comets, importantly, the lunar impactor types inferred by these HSE methods are compositionally distinct from the types of primitive carbonaceous chondrites thought to be most akin to cometary materials (i.e., the CM or CI or Tagish Lake meteorite types: Brandon et al. 2005; Liu et al. 2015). This implies that asteroid sources rather than comets or Kuiper belt objects were the dominant source of the basin-forming projectiles (Kring and Cohen 2002; Norman et al. 2006; Walker et al. 2015).

Lunar regolith, at the interface between the Moon and surrounding space environment (Hörz et al. 1991; McKay et al. 1991; Lucey et al. 2006; Spray, 2016; Wieler, 2016), was sampled by every Apollo mission (Morris et al. 1983). Immature regoliths, exposed to space for only a few thousand to few million years, include those collected from shadowed and permanently-shaded environments under or adjacent to boulders (for example, sample 63320 from Apollo 16 and samples 72320 and 76240 from Apollo 17). Mature lunar regoliths exposed to space for hundreds of millions of years have had $\sim 1.6-3.4 \%$ siderophile-rich material added with average CI/CM-like chondritic meteorite compositions (Papike et al. 1991; Korotev et al. 2003; Wolf et al. 2009). This component is rarely in the form of intact meteorite fragments (see below), but typically originates from microscale iron particles bound up in impact melt breccias and glassy agglutinate structures, loose metal and sulphide fragments reworked from these components, and metal-sulphide spherules (see examples in Fig. 1). Nitrogen isotope analysis of such lunar soils and agglutinates also supports an exogenously contributed micrometeorite (sometimes referred to in the literature as 'planetary') chemical component in the lunar regolith (Hashizume et al. 2000, 2002; Füri et al. 2012; Füri and Marty 2015). Furthermore, a cometary or carbonaceous chondrite addition to Apollo 16 soil 61221 has been postulated by Gibson and Moore (1973) using evidence from bulk carbon and other volatile element signatures. Morgan et al. (1978) also used soil HSE and volatile element contents to infer that Copernicus $(0.8 \mathrm{Ga})$ was possibly formed by a primitive cometary impactor. Graphitic carbon identified in Apollo 17 impact melt breccia 72255 has been interpreted as being sourced from a carbonaceous-rich primitive meteorite or comet (Steele et al. 2010), and carbon-rich coatings on the surfaces of lunar volcanic glasses have also been attributed to exogenous implantation by a cometary or carbonaceous chondrite impactor (ThomasKeprta et al. 2014).

\subsubsection{Direct Evidence}

Fragments of exogenous contributions to the lunar regolith provide direct evidence of the types of small bodies striking the Moon at different times through the last 3.8 billion years 

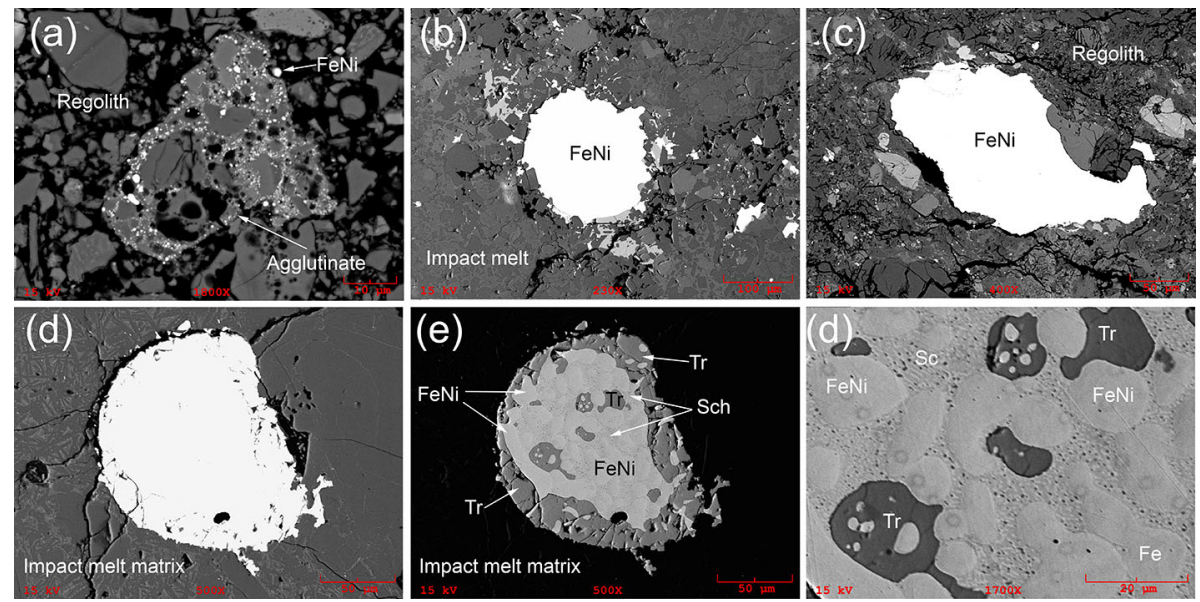

Fig. 1 Back scatter electron images of Fe-metal and sulphide components in Apollo regolith breccia samples. a Small FeNi metal blebs bound up in a vesicular agglutinate in Apollo 16 regolith breccia 65475 . b Large FeNi metal assemblages found in a crystalline (plagioclase, pyroxene) impact melt breccia clast extracted from regolith breccia 60016. These metal particles are often reworked from their parent melt impact rocks, and are found as Fe-Ni fragments in the regolith sample, for example as shown in $\mathbf{c}$, which is a FeNi particle found in the matrix of regolith breccia 60255. d-e Metal-rich melt spherule bound in the feldspathic glassy splash coat of regolith breccia 60275. The contrast has been stretched in $\mathbf{e}$ and $\mathbf{f}$ showing structural variation with a troilite $(\mathrm{FeS}) \mathrm{rim}$ and with rounded blebs of Fe (85-88 wt\%) Ni (12-16 wt \%) metal (Fe) that contains $\mathrm{P}$ at $\sim 1$ wt\% level, troilite (Tr) and a P-rich schreibersitic (Sc) interstitial groundmass (speckled phase). Images taken by K. Joy

(e.g., see discussion in NRC 2007; Armstrong et al. 2002; Chapman 2002; Fries 2010; Joy et al. 2012 and references therein).

\subsubsection{Asteroids}

At the present day, where the Moon is a distance of 60 Earth radii away from the Earth, Earth-Moon crossing asteroid impactors strike the Moon with mean (model dependent) impact velocities of between 17.4 and $19.7 \mathrm{~km} / \mathrm{s}$ (Le Feuvre and Wieczorek 2011; Yue et al. 2013). The highest probability impact velocity is of $12 \mathrm{~km} / \mathrm{s}$ (Le Feuvre and Wieczorek 2011), and $25 \%$ of all impactors strike at velocities of $<12 \mathrm{~km} / \mathrm{s}$ (Yue et al. 2013). At the latter end of basin formation ( 3.9-3.6 Ga) models suggest that Moon was closer to the Earth (21-51 Earth radii away: Zharkov 2000; Suavet et al. 2013). A closer proximity to the Earth may have enhanced lunar impactor speeds due to Earth's gravitational focusing effect (e.g. Marchi et al. 2012).

Survivability of such projectile fragments to the Moon's surface may be possible at these collisional velocities and associated peak shock pressure regimes. However, preservation of impactor material will be facilitated further by relatively low $(<4 \mathrm{~km} / \mathrm{s})$ impact velocities (Crawford et al. 2008; Armstrong 2011), by oblique ( $<10$ degrees) impact angles where material can be spalled off the projectile during impact (Pierazzo and Melosh 2000; Bland et al. 2008; Svetsov and Shuvalov 2015; Schultz and Crawford 2016), and by incorporation of impactor material into central peaks formed during the crater formation process (Yue et al. 2013). Recent laboratory experiments have also shown that the material properties, specifically porosity, of the impactor target material further helps to 
promote survivability of the silicate and metal impactors (Nagaoka et al. 2014; Daly and Schultz 2016; Avdellidou et al. 2016), suggesting that regions of the lunar crust with thicker and more porous regolith/megaregolith may better preserve surviving fragments of projectiles.

Examples of surviving asteroidal material found in lunar regolith samples (see Fig. 2 for images) are listed in Table 1 along with evidence for timing of their delivery.

The following debris has been recovered from lunar soils: the Apollo 12 carbonaceous chondrite Bench Crater meteorite (Wood et al. 1971; McSween 1976; Fitzgerald and Jones 1977; Zolensky et al. 1996; Zolensky 1997; Joy et al. 2013); the Hadley Rille enstatite chondrite meteorite (Haggerty 1972; Rubin 1997); iron meteorites found in Apollo 11 regolith samples 10084 (McKay et al. 1970) and 10085 (Quaide and Bunch 1970; Goldstein et al. 1970); an Ir-rich iron micrometeorite from Apollo 16 core 60014 (Jolliff et al. 1993); and a possible mesosiderite meteorite located in soil 10084 (Wood et al. 1970).

The following fragments have been found within the matrix of regolith breccia samples: a chondritic fragment found within lunar meteorite Pecora Escarpment 02007 (Day et al. 2006; Liu et al. 2009; Joy et al. 2012) and young Apollo 16 regolith breccias (Joy et al. 2012); ultra-magnesian chondritic-silicate particles found in Apollo 16 ancient regolith breccias (Warren and Wasson 1979; Joy et al. 2012); and a potential achondritic meteorite fragment in lunar meteorite MacAlpine Hills 88105 (Joy et al. 2014).

Other meteorite candidate fragments with mineral chemistries dissimilar to lunar rocks are discussed by Gross and Treiman (2010), Gross (2014), and Fagan et al. (2014). All these fragments are very small, ranging from only a few microns to a few $\mathrm{mm}$ in size and have textures that are distinct from interplanetary dust particles (Fig. 2). Larger hand specimen-sized meteorites, such as those found on Earth (Meteoritical Bulletin database 2016) and Mars (Ashley 2015 and references therein), have not yet been located in the Apollo, Luna or lunar meteorite sample collections.

\subsubsection{Cometary Impactors}

Recognition of cometary debris in the lunar regolith would require evidence of mineralogical, composition and isotopic similarity to previously analysed cometary particles, such as those returned by the NASA Stardust mission to comet 81P/Wild-2 and the terrestrial interplanetary dust particle (IDP) collection (e.g., Rietmeijer 1998; McKeegan et al. 2006; Zolensky et al. 2006; Ishii et al. 2008; Busemann et al. 2009; Frank et al. 2014). To date, given these constraints, no cometary silicate debris has been directly identified in lunar regolith samples.

However, recent hydrocode modelling work by Svetsov and Shuvalov (2015) suggests that whilst $99 \%$ of all water is vaporised in cometary impacts, a small portion of hydrated minerals can survive the impact event and $\sim 1.5 \%$ of all lunar craters could potentially contain this hydrated mineral debris. A larger fraction of comet impactors are lost from the Moon than asteroids, because they hit at higher velocities. For example, hydrocode simulations suggest for impact angles of 45 degrees, $86 \%$ of cometary debris escapes in an expanding high-velocity ejecta plume, while only $42 \%$ of asteroid debris escapes (Artemieva and Shuvalov 2008). When integrated over reasonable impact velocities, $93.5 \%$ of comet and $83.5 \%$ of asteroid debris entrained in the plume may have been lost (Ong et al. 2010). However, overall there is a retention factor on the order of $\times \sim 2-4$ that favours survivability of asteroid material over cometary (Joy et al. 2012). 

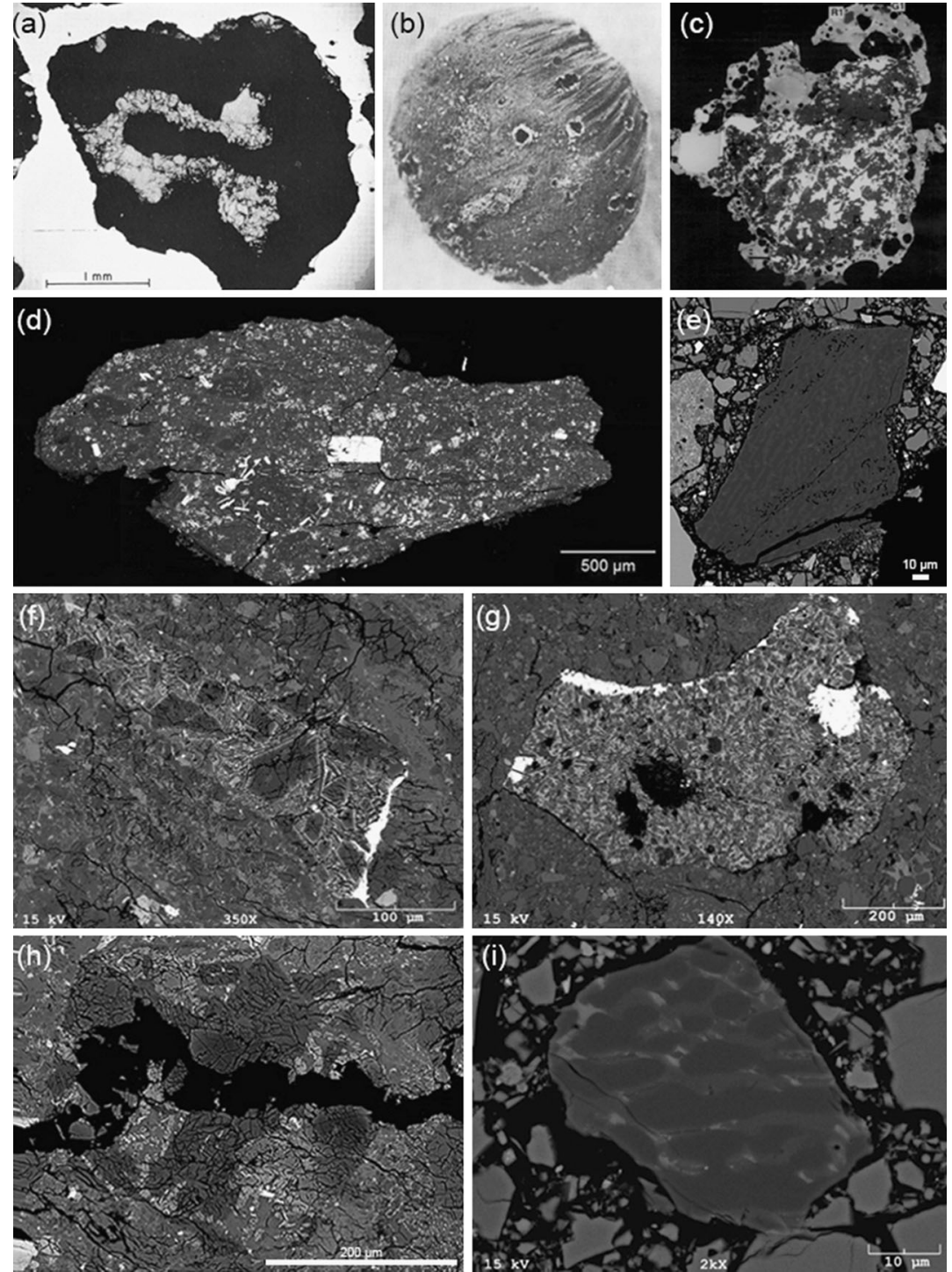

Fig. 2 Reflected light and back-scatter electron images of different meteoritic fragments located in different lunar samples. a Postulated mesosiderite fragment found in Apollo 11 soil 10084 (image after Wood et al. 1970); b Mini-Moon: a 4 mm size melted Fe-metal meteorite fragment found in Apollo 11 soil 10085 (image after Goldstein et al. 1970); c Hadley Rille enstatite chondrite fragment coated in an agglutinated rim, recovered from Apollo 15 soil 15602 (image after Rubin 1997). d Bench Crater meteorite found in Apollo 12 soil 12037 (Zolensky 1997, image K. Joy). e Ultra-magnesian mafic fragment (UMMF) located in ancient regolith breccia 60016 (image after Joy et al. 2012). f Olivine-phyric meteorite found in young regolith breccia 60255 (image after Joy et al. 2012). g Fragment found in lunar meteorite regolith breccia Pecora Escarpment 02007 (Day et al. 2006; image after Joy et al. 2012). h Mg-rich K-rich fragment found in lunar meteorite regolith breccia MAC 88105 (image after Joy et al. 2014). i Ultra-magnesian mafic fragment (UMMF) located in ancient regolith breccia 60016 (image after Joy et al. 2012). Images modified from original sources 


\subsubsection{Impactors Derived from Other Planets}

To-date no meteorites derived from other planets have been definitively identified in lunar regolith samples (Table 1). Identification and preservation of ejected planetary material (e.g., from the early Earth during the Hadean or Archean, or Noachian Mars) could answer outstanding questions related to the early geological, and possibly biological, evolution of the terrestrial planets (e.g. Armstrong et al. 2002; Crawford et al. 2008; Matthewman et al. 2015).

\section{Locating Projectile Debris in Lunar Samples}

Locating, classifying and characterising planetary, asteroidal or cometary projectile remnants in lunar regolith samples should be considered during future collection of samples from the Moon by robotic or human explorers, by preliminary examination teams, and during routine scientific analysis of lunar regolith samples (Fries 2010). We recommend the following approaches for the initial identification of such exogenous material in lunar samples:

\subsection{Iron-Bearing Meteorites from Protoplanetary Cores and Primitive Asteroid Bodies}

Meteoritic metal particles are common in lunar soil samples and regolith breccias (Fig. 1) (e.g. Goldstein and Yakowitz 1971; Wittmann and Korotev 2013), however, most have been impact-modified from their parent bodies; for example, impactor metal (Fig. 1c-f) has often been melted during the impact event, and then precipitated out of the melt sheets or ejecta clouds (e.g. Blau and Goldstein 1975 and references therein; Goldstein et al. 1975; Wänke et al. 1978). Locating metal-bearing asteroid debris in bulk lunar soils could be performed using magnetic separation techniques (e.g. Housley et al. 1972), or chemically fingerprinting large quantities of soil particles using non-destructive analytical methods (Jolliff et al. 1993). Petrographic examination of separated metal fractions will need to be conducted to distinguish unmodified metal-bearing impactors (Wood et al. 1970; Jolliff et al. 1993). It has been postulated that large amounts of unmodified iron-rich metallic meteorites may survive basin-forming events, accounting for some observed magnetic anomalies on the lunar surface (Wieczorek et al. 2012), although this is still under debate (Cahill et al. 2014).

Identification of different iron oxidation states using Mössbauer spectroscopy of bulk soils could be employed to locate soils bearing oxidised phases such as hematite and magnetite (e.g. Housley et al. 1972; Morris et al. 1998). Such Fe-oxide phases are extremely rare in lunar samples (Joy et al. 2015), but are common phases in aqueously altered (i.e. oxidised) primitive meteorites like Bench Crater (Zolensky 1997), and may indicate that the host regolith contains primitive asteroid or cometary (Stodolna et al. 2012) derived debris.

\subsection{Silicate Fragments from Primitive and Differentiated Asteroid Bodies and Comets}

Locating silicate fragments and mineral debris is often a more labour intensive task, involving careful high resolution in situ chemical sample mapping (Joy et al. 2011b, 


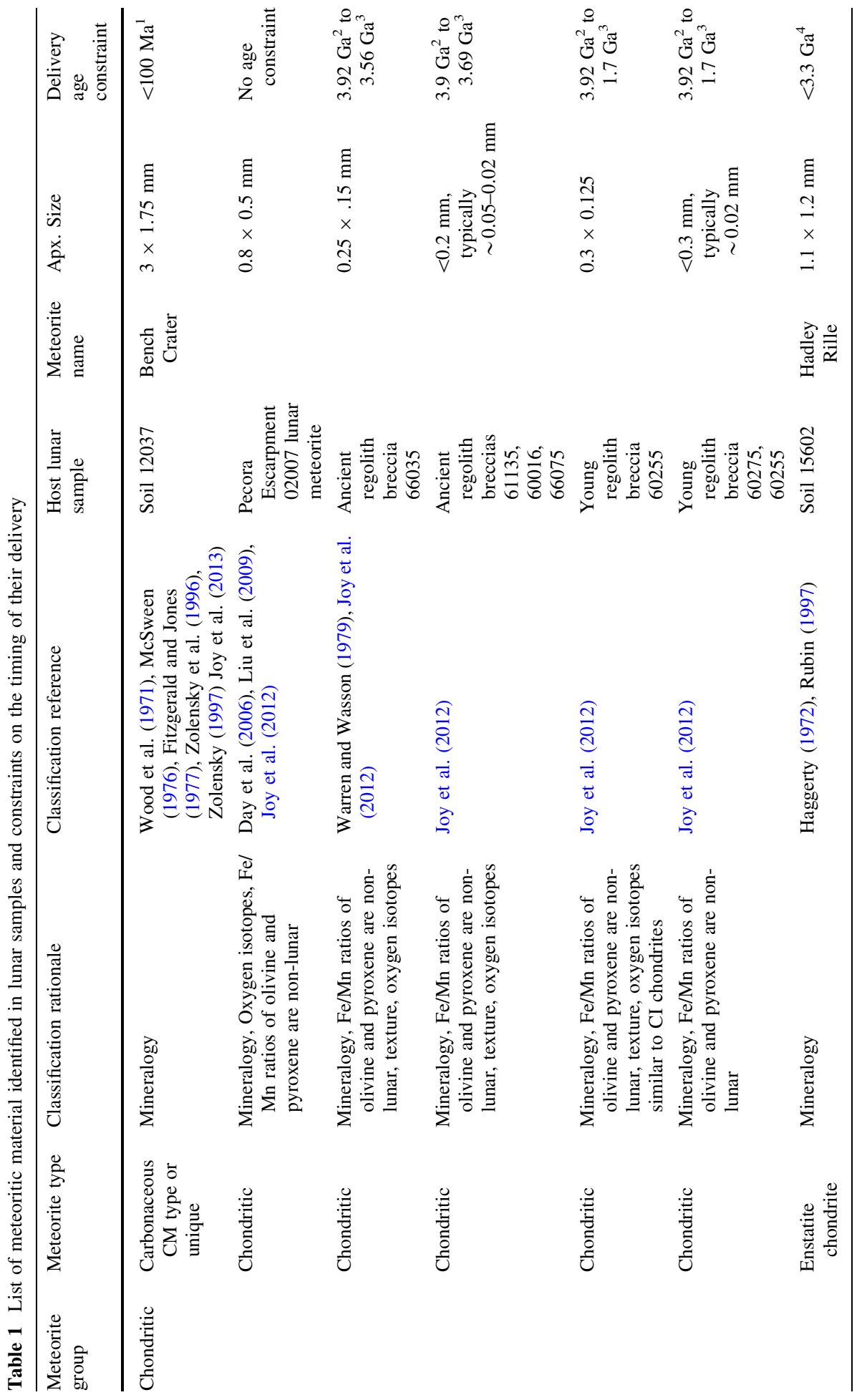




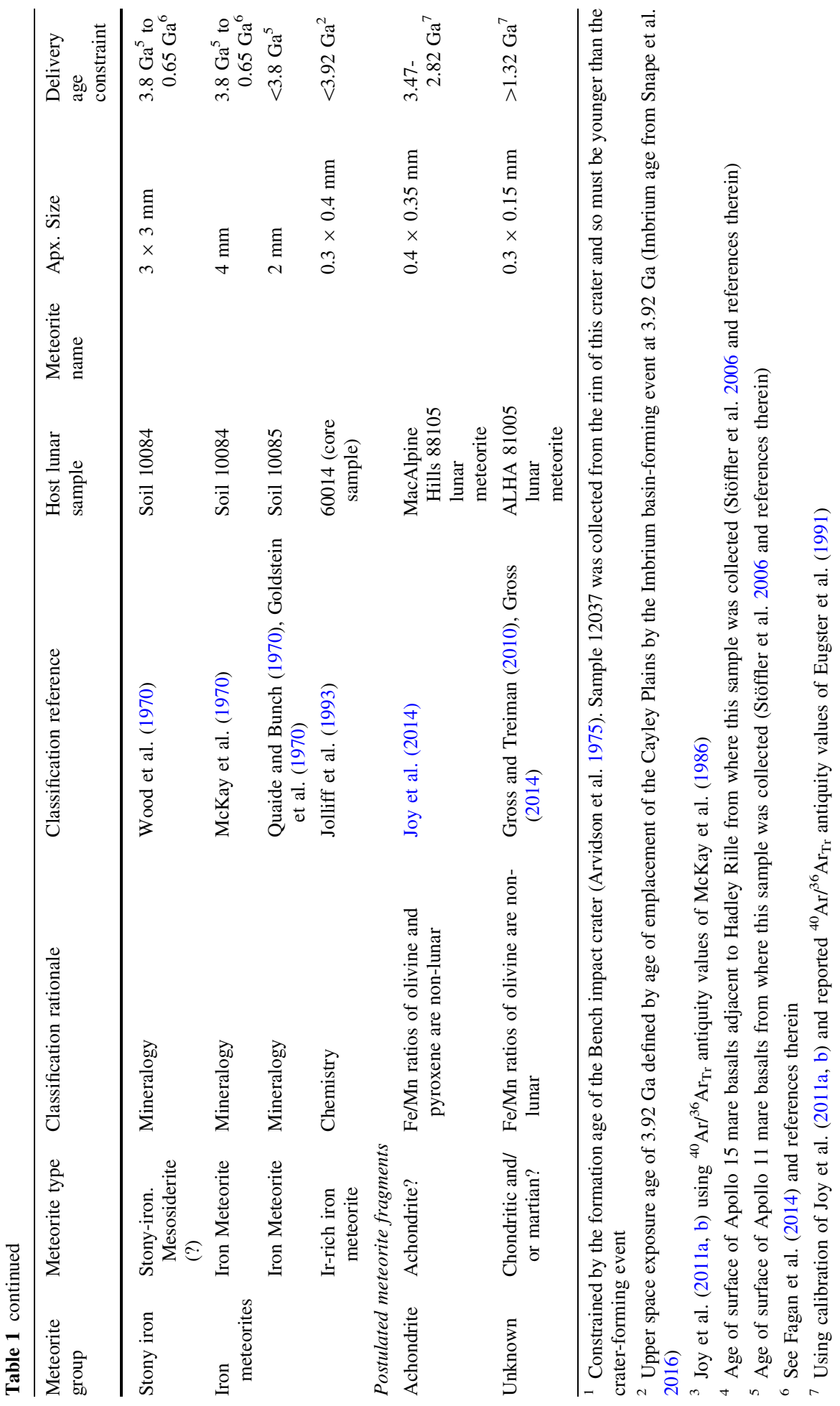


2012, 2014; Fagan et al. 2015, 2016), or more serendipitous discoveries during routine optical microscopy (Wood et al. 1971; Haggerty 1972), spectroscopic analysis (e.g. RAMAN or Fourier transform infrared (FTIR)), or electron microprobe chemical analysis (Warren and Wasson 1979; Day et al. 2006) of minerals in polished petrographic sections.

Challenges remain as to being able to distinguish primitive carbonaceous chondritic mineral debris (i.e. chondrule fragments, amoeboid olivine aggregates, matrix minerals, amorphous silicates, carbonates) from that of surviving cometary material. Therefore, careful electron microprobe or TEM chemical analysis (e.g. Zolensky et al. 2008; Frank et al. 2014) and oxygen isotopic fingerprinting (e.g. Nakashima et al. 2012) on recovered fragments is required to compare with the existing planetary materials databases (i.e. samples returned by the NASA Stardust mission to comet $81 \mathrm{P} /$ Wild-2 and the IDP and meteorite collections).

\subsection{Volatile-Rich Material from Primitive Asteroids, and Comets}

Locating and characterising volatile-rich or organic-phase debris sourced from comets or primitive asteroids (Svetsov and Shuvalov 2015) will require using non-destructive methods like RAMAN or FTIR spectroscopy that fingerprint organic molecules or phyllosilicates (Fries and Steele 2007) or thermally-altered remnants of such material, which have a characteristic texture and mineralogy (Zolensky et al. 2008; Burchell et al. 2014a).

\subsection{Material Derived from the Earth and Other Planets}

It is hypothesised that the lunar surface may harbour material ejected from the Earth in impact events (Gutiérrez 2002; Armstrong et al. 2002; Crawford et al. 2008; Armstrong 2011; Burchell et al. 2014b). For example, it is estimated that on average there is 1-2 ppm of terrestrial material at the lunar surface today, however, some areas of the surface may have higher concentrations (Armstrong 2011). As impact collision speeds from terrestrial material are relatively low (peaking at $\sim 3 \mathrm{~km} / \mathrm{s}$; Armstrong 2011), it has been demonstrated that terrestrial material may well survive peak shock pressures remaining intact after impact (Crawford et al. 2008; Burchell et al. 2014b). Such considerations imply the possibility that the lunar surface preserves material delivered from the Hadean or early Archean Earth, preserving key chemical and isotopic information about the early history of our planet and potentially even preserving remnants of fossil life (Burchell et al. 2014b) and early biological processes (Matthewman et al. 2015). Remnants of such early Earth geological materials might challenging to identify in regolith materials, but could be identified from the presence of mineral or rock debris from komatiite lavas (that were dominant in the early Earth's crust), hydrated or oxidised minerals, sedimentary rocks (e.g. mudstones, limestone, sandstone), and examples of continental crust (e.g. granites bearing hydrated micaceous minerals) and their metamorphosed equivalents (e.g. garnet schists, gneisses etc.). Isotopic or chemical fingerprinting of such material may help to distinguish it from lunar rocks: for example, although oxygen isotope compositions of Earth and Moon igneous rocks are very similar (Young et al. 2016 and references therein), there are well established compositional differences between terrestrial and lunar igneous rock-forming minerals (e.g., Fe/Mn ratios and differences in minor elements in olivine and pyroxene phases: Papike et al. 2003; Karner et al. 2003, 2006, and alkali-elements in plagioclase: Karner et al. 2004), which can be used to determine planetary heritage (see discussion in Joy et al. 2014). 
As we find meteorite samples from Mars here on Earth (Gladman et al. 1996; Meteoritical Bulletin database 2016), impact ejecta from the martian surface could also be plausibly found in the lunar regolith (Armstrong et al. 2002). Such samples could be identified by key chemical, isotopic or noble gas signatures (Papike et al. 2003; Karner et al. 2003, 2004, 2006), and/or by radiometric ages similar to the young (by lunar standards) lava flows sampled by the SNC (Shergottite-Nakhla-Chassigny) martian meteorite groups. Moreover, as Earth's thick atmosphere selectively inhibits more porous sedimentary rock and soil-like samples from surviving entry (Brack et al. 2002), it may be that the lunar surface preserves a better archive of martian regolith breccias and sediments.

Impact ejecta from the surface of planet Mercury are predicted to encounter the EarthMoon system at about half the likelihood than martian sample encounters (Gladman and Coffey 2009). Recognition of such mercurian meteorite debris may be challenging as to date we have no direct samples of Mercury for which to compare with (Love and Keil 1995; Vaughan and Head 2014; Weber et al. 2016). However, recent mapping efforts by the MESSENGER spacecraft provide mineralogical and compositional constraints of the nature of Mercury's regolith for which to use as a basis of comparison (e.g. Nittler et al. 2011; Peplowski et al. 2015; Weider et al. 2012, 2014; Stockstill-Cahill et al. 2012; Vaughan and Head 2014).

Meteoritic material originating from Venus is considered to be much more unlikely given the challenges of successfully surviving the ejection event through the dense venusian atmosphere (Gladman et al. 1996; Armstrong et al. 2002), however, it may be possible that in the past, if Venus's atmosphere was thinner, impact ejecta may have escaped to be thrown onto a Earth-Moon crossing orbit resulting in delivery to the lunar surface (see discussion in Armstrong et al. 2002; Chapman 2002).

\section{Constraining Timing of Delivery}

The temporal record of projectile delivery to the Moon is key for understanding the link to causes of small body migration throughout the Solar System.

Discoveries of fragments of projectiles in ancient regoliths (formed $>3.5 \mathrm{Ga}$ ) provide evidence of the types of Earth-Moon-crossing impactors during the latter stages of the basin-forming epoch, addressing key questions about early Solar System dynamics (see Sect. 1). The archive may potentially also include terrestrial sourced meteorites, originating from the Earth during the Eoarchean and Palaeoarchean eras, coincident with the timing of the emergence and proliferation of life on Earth (e.g. Walker et al. 1983). Discoveries of Pre-Noachian and Noachian martian meteorites in ancient lunar regolith (Armstrong et al. 2002) may unlock critical information about Mars's ancient hydrosphere, atmosphere and geological activity, leading to a greater understanding of habitability (e.g. Beard et al. 2013; Blamey et al. 2015; Usui et al. 2015).

Younger regoliths formed $<3.5 \mathrm{Ga}$ provide a window to understanding the sources of Earth-Moon-crossing impactor populations during a window of declining bombardment rates (Joy et al. 2011a, b, 2012; Fagan et al. 2014). These younger samples potentially provide an archive of the types of Near Earth Objects that played a role in episodic mass extinction events here on Earth (Fagan et al. 2014, 2015, 2016) and help to better understand the causes of such spikes (for example, the breakup of an asteroid like the L-chondrite parent body at 500 Ma: Haack et al. 1996). 
Constraining regolith 'ages', and thereby shedding light on when projectiles were delivered to the Moon, can be challenging. The different types of geological settings that preserve temporal regolith records are discussed below, and are depicted in Fig. 3.

\subsection{Soils}

The types and duration of regolith space exposure can be determined by different indicators. This includes the ferromagnetic resonance (FMR) maturity index $\left(\mathrm{I}_{\mathrm{S}} / \mathrm{FeO}\right)$, which has shown to be proportional to exposure in the top $1 \mathrm{~mm}$ of regolith (Morris 1976, 1978). $\mathrm{I}_{\mathrm{s}} / \mathrm{FeO}$ is the ratio of the intensity of the FMR resonance from submicroscopic iron $\left(\mathrm{I}_{\mathrm{s}}\right)$ to the bulk rock $\mathrm{FeO}$ abundance. The maturity index is used to divide lunar samples into three levels of increasing surface exposure: immature $\left(\mathrm{I}_{\mathrm{s}} / \mathrm{FeO}=0-29\right)$, submature $\left(\mathrm{I}_{\mathrm{s}} /\right.$ $\mathrm{FeO}=30-59)$, and mature $\left(\mathrm{I}_{\mathrm{s}} / \mathrm{FeO} \geq 60\right.$ ) (Morris 1976, 1978). This upper surface exposure index correlates well with other surface exposure indicators such as the trapped ${ }^{36} \mathrm{Ar}$ component derived from the solar wind (Fig. 4), agglutinate content and grain size.

Quantitative measures of exposure age include measuring cosmogenic nuclides produced from the interaction with target elements (e.g. O, Mg, Ca, K, Si) in the top few meters of lunar regolith (Eugster et al. 2001 and references therein; Lorenzetti et al. 2005). Cosmogenic noble gas isotope abundances $\left({ }^{3} \mathrm{He},{ }^{21} \mathrm{Ne},{ }^{38} \mathrm{Ar},{ }^{81} \mathrm{Kr},{ }^{126} \mathrm{Xe}\right)$ can provide information regarding the history of the sample during residence in the regolith, surface maturity, and the sample's depth of burial (i.e. shielding from cosmic rays) (Eberhardt et al. 1976; Eugster et al. 2001; Lorenzetti et al. 2005), as concentrations of these gases in indigenous lunar samples before cosmic ray exposure are deemed negligible.
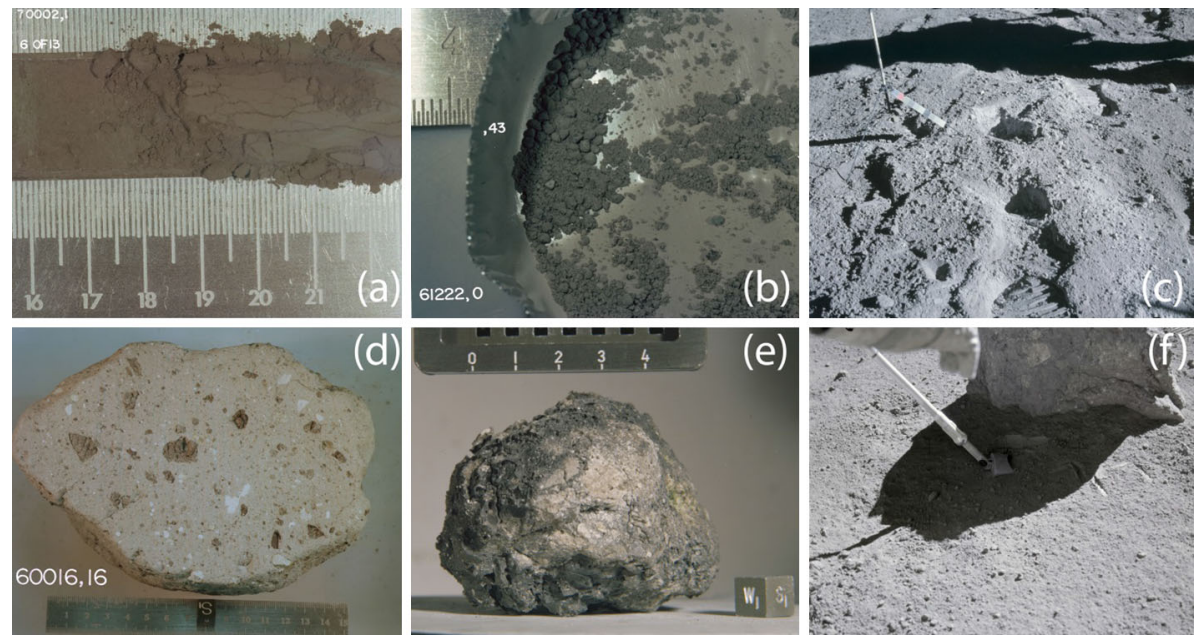

Fig. 3 Examples of different types of Apollo regolith records. a Section of the Apollo 17 deep drill core 70002 (NASA photo S77-20158). b Apollo 16 trench soil 61222 after sieving from parent soil 61220 (NASA photo S80-40445). c Post collection of trench soil sample 61220 from Plum crater at the Apollo 16 landing site (NASA photo AS16-114-18410). d Regolith breccia sample 60016, which is thought to have been fused from a soil to a rock $\sim 3.7$ billion years ago (NASA photo S78-34417). e Regolith breccia sample 60275, which is thought to have been fused from a soil to a rock $\sim 2.35$ billion years ago, and covered with a dark glassy splash coat (NASA photo S72-43223). Scale bar ticks in a, b, d and e are $1 \mathrm{~cm}$. f Scoop sample collection of shadowed Apollo 16 soil 69440 from Station 9 of the Apollo 16 landing site (NASA photo AS16-107-17561). Adapted from Fig. 9 of Crawford et al. (2014) 

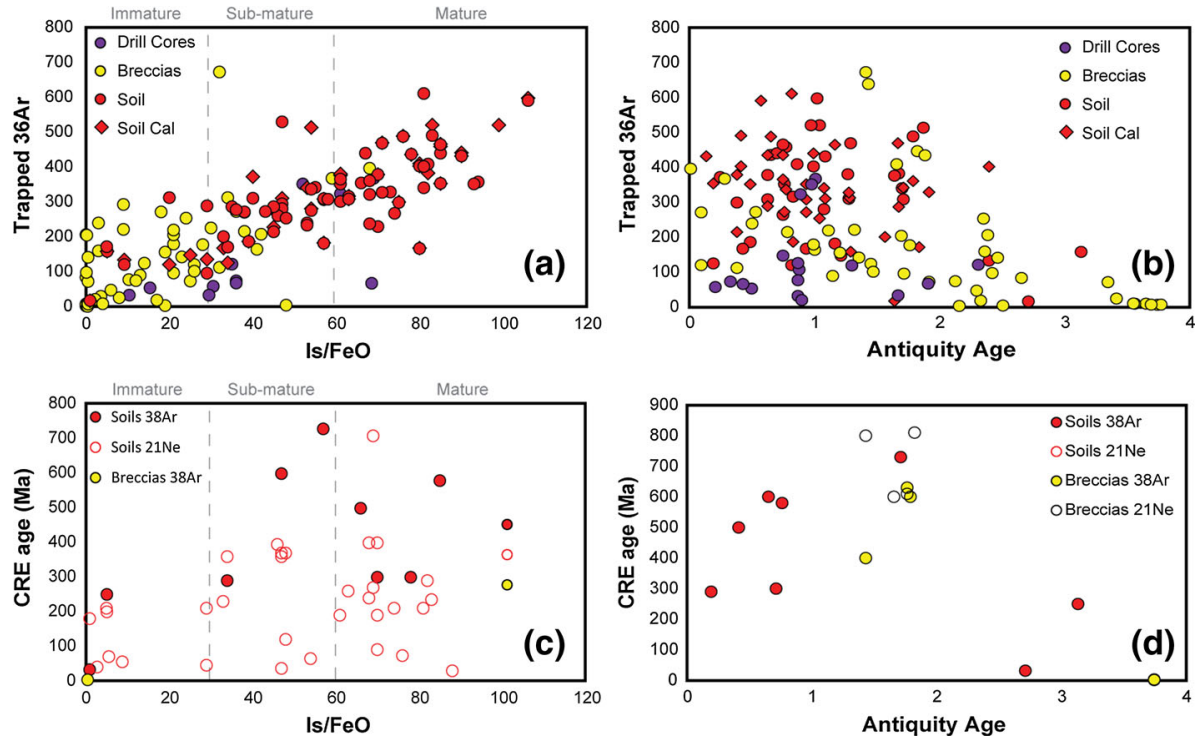

Fig. 4 A comparison of noble gas and maturity literature data for Apollo soils, breccias and drill cores showing the relationship between surface exposure (i.e. top millimeter of the lunar regolith) and cosmic ray exposure age (i.e. top meter of the lunar regolith). a Trapped ${ }^{36} \mathrm{Ar}$ versus $\mathrm{I}_{\mathrm{s}} / \mathrm{FeO}$ : Trapped ${ }^{36} \mathrm{Ar}\left(\times 10^{-6}\right.$ cc.STP/g) refers to the solar wind implanted ${ }^{36} \mathrm{Ar}$ and $\mathrm{I}_{\mathrm{s}} / \mathrm{FeO}$ is the ratio of the intensity of the FMR resonance from submicroscopic iron $\left(\mathrm{I}_{\mathrm{s}}\right)$ to the bulk rock FeO abundance. "Drill cores" data represents the $>75 \mu \mathrm{m}$ grain size fraction. "Soils Cal" data are calculated from noble gas values in the literature based on a trapped-cosmogenic decomposition mixing line assuming ${ }^{36} \mathrm{Ar} /{ }^{38} \mathrm{Ar}_{\mathrm{cos}}=0.65$ and ${ }^{36} \mathrm{Ar} /{ }^{38} \mathrm{Ar}_{\mathrm{tr}}=5.32$. Grey dashed lines indicate the $\mathrm{I}_{\mathrm{s}} / \mathrm{FeO}$ soil classification for an immature (0-29 units), sub-mature (30-59 units) and mature ( $>60$ units) soil (Morris 1978). b Trapped ${ }^{36} \mathrm{Ar}$ versus Antiquity age: antiquity age can be determined using the ${ }^{40} \mathrm{Ar} /{ }^{36} \mathrm{Ar}_{\text {tr }}$ ratio which is empirically related to the time gas became closed off from further exposure i.e. breccia formation age. $\mathbf{c} \mathrm{CRE}$ age versus $\mathrm{I}_{\mathrm{s}} / \mathrm{FeO}$ : $\mathrm{CRE}$ - cosmic ray exposure age (Ma) is the duration of space exposure, "21 $\mathrm{Ne"} \mathrm{and} \mathrm{"38} \mathrm{Ar}$ " are the CRE age as calculated from the cosmogenic ${ }^{21} \mathrm{Ne}$ and ${ }^{38} \mathrm{Ar}$ respectively. Grey dashed lines indicate the $\mathrm{I}_{\mathrm{s}} / \mathrm{FeO}$ soil classification for an immature (0-29 units), sub-mature (30-59 units) and mature ( $>60$ units) soil (Morris 1978). d CRE age versus Antiquity age. Data are taken from a range of literature sources (CRE ages: Kirsten et al. 1972; Hintenberger and Weber 1973; Bogard et al. 1974; Hintenberger et al. 1975; Eberhardt et al. 1976; Weber and Schultz 1978; Trapped Ar data: Pepin et al. 1970, 1974; Hintenberger et al. 1970, 1974, 1975; Hintenberger and Weber 1973; Bogard et al. 1973, 1974; Bogard and Nyquist 1972, 1973; Kirsten et al. 1972; Walton et al. 1973; Eberhardt et al. 1976; Bogard and Hirsch 1975; McKay et al. 1986, 1989; Sample Antiquity ages: Fagan et al. 2014; Is/FeO data: Morris 1978; Morris et al. 1979; Morris and Gose 1977; Bogard et al. 1982; McKay et al. 1986, 1989; Basu et al. 2000)

Sampling of subsurface regoliths by trenching (Fig. 3b, c, f), drive core extraction (down to $\sim 80 \mathrm{~cm}$ ), or drilling (Luna and Apollo mission drill cores extended down to $\sim 2-3 \mathrm{~m}$ respectively; Fig. 3a) provides access to lower stratigraphic horizons. However, as discussed by Fagan et al. (2014) the collection depth of a core/tube sample is not necessarily correlated with regolith formation ages, due to heterogeneous vertical and lateral mixing histories.

In summary, deciphering the surface exposure and exposure age provides an understanding of the history of a sample during the residence time in the upper or near surface regolith environment. However, neither of these methods tells us when in the past the exposure event(s) occurred. As the majority of lunar rocks have experienced complex histories in the regolith, due to the changing influx of projectile material, this age may 
represent several episodes of near-surface residence. Fragments of meteorites found in both present day lunar soils and extracted from core samples potentially have been reworked from underlying stratigraphic horizons, so determining an upper age limit of meteorite delivery can be approximated using knowledge of the underlying geological unit age (i.e. lava flow age, crater ejecta blanket or impact melt sheet age).

\subsubsection{Regolith Breccias}

Better constrained temporal records are preserved in regolith breccias collected at the present day lunar surface. Regolith breccias are lithified samples of the regolith that have been fused together by impact shock and thermal metamorphism (Fig. 3d, e). In effect, they are time capsules (McKay et al. 1986, 1989; Korotev 1996; Spudis and Taylor 2009; Crawford et al. 2007, 2009, 2010; Joy et al. 2011a, b, 2012, 2014; Fagan et al. 2014): once they have been turned from a soil into a coherent rock they are closed to solar wind exposure and can no longer acquire a meteoritic component. The timing of this closure event (i.e. a lower regolith age limit) can be estimated by measuring bulk argon isotopes to derive an argon antiquity age (McKay et al. 1986; Eugster et al. 2001; Joy et al. 2011a, b; Fagan et al. 2014), although this approach requires further calibration using additional samples (Wieler 2016).

In general regolith breccias, such as those collected at the Apollo 16 site, fall into two categories: ancient $(>3.5 \mathrm{Ga})$ and young $(<3.5 \mathrm{Ga})$ ages determined by this antiquity indicator (Fagan et al. 2014). Ancient regolith breccias are typically immature in regards to surficial space exposure (McKay et al. 1986; Korotev 1996), and younger soils and breccias display a range of maturities (McKay et al. 1989; Joy et al. 2011a, b; Fagan et al. 2014). This is linked to the changing impact flux on the Moon from large-scale megaregolith formation during the basin-forming epoch, to the more recent periods of the less energetic "gardening" process (McKay et al. 1986).

Alternatively, breccia lithification event ages can be constrained by determining the timing of formation of splash glassy impact coats (known as splash coats) that often drape breccias samples at the Apollo landing sites (Fig. 3e: e.g. See et al. 1986; Morris et al. 1986; Borchardt et al. 1986; Joy et al. 2015), sealing them from further regolith processes. Like present day soils, upper age estimates on regolith age are more challenging to constrain.

\subsubsection{Palaeoregoliths}

The best temporally constrained records are likely to be preserved in trapped ancient 'palaeoregolith' horizons found sandwiched between layers of radiometrically datable geological units. Possible examples include regolith layers trapped between discrete lava flows (e.g. Fig. 5), between a lava flow and an overlying pyroclastic deposit, and regolith buried by crater ejecta blankets and/or impact melt flows (Crawford et al. 2007, 2010; McKay 2009; Fagents et al. 2010; Rumpf et al. 2013; Crawford and Joy 2014).

Some of these trapped regoliths could have been affected by thermal or physical disruption due to the emplacement of the capping layer (be it a lava flow, or hot impact ejecta blanket). The thermal heating issue has been explored in detail by Fagents et al. (2010), Rumpf et al. (2013) and Matthewman et al. (2015), who demonstrate conditions for survivability of volatile and organic rich material delivered from exogenous sources.

Locating and sampling palaeoregolith deposits will likely be an important objective of future lunar exploration activities (Crawford et al. 2014; Crawford and Joy 2014). 
T1. Lava flow emplaced

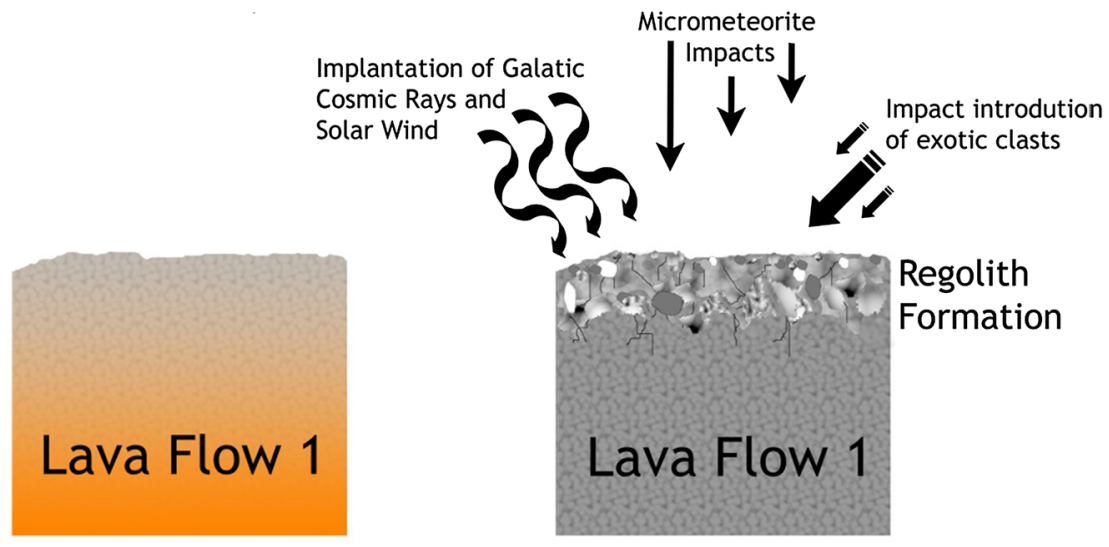

T3. New lava flow emplaced

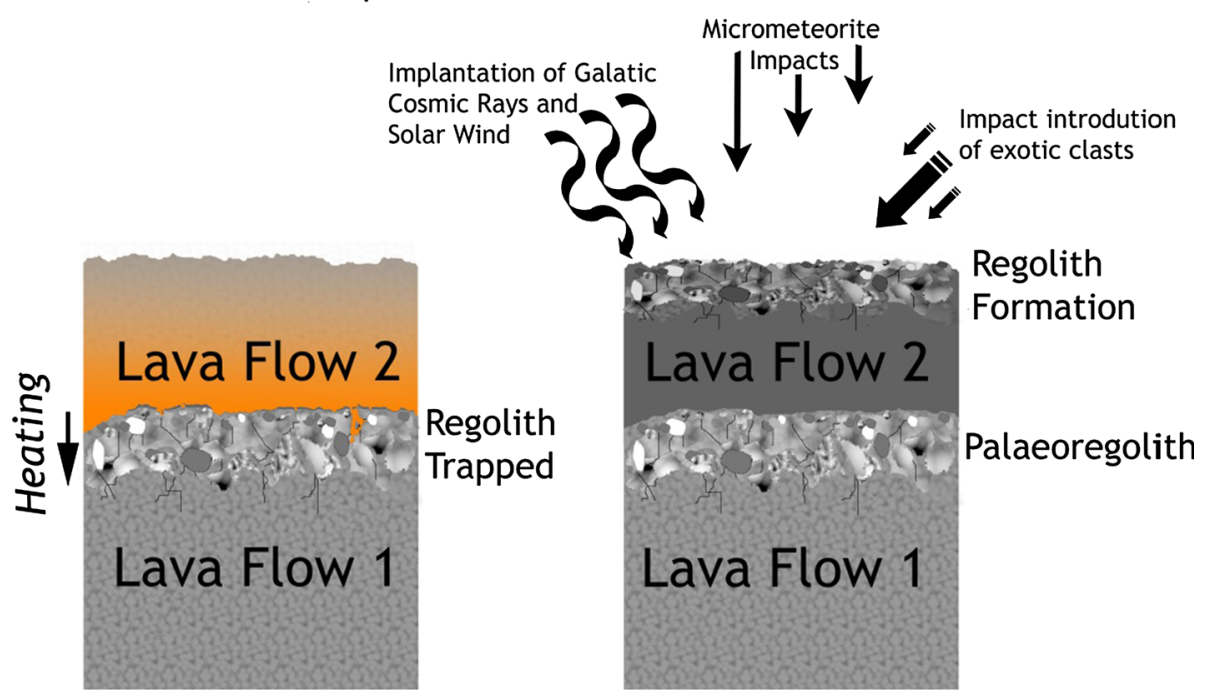

Fig. 5 Schematic representation of the formation of a palaeoregolith layer trapped between distinct lava flow units that could be dated to bracket the window of regolith development and, thus, constrain the delivery interval of any preserved projectile debris: 1 A new lava flow is emplaced and cools. 2 Impactors immediately begin to develop a surficial regolith, where the post-basin epoch rate of gardening is estimated to have ranged from $\sim 3$ to $5 \mathrm{~mm}$ of new regolith per million years at $\sim 3.8 \mathrm{Ga}$ to be about $1 \mathrm{~mm} / \mathrm{Myr}$ from $\sim 3.5 \mathrm{Ga}$ to the present day (Hörz et al. 1991). Impactor debris, solar wind particles, galactic cosmic rays and "exotic" material derived from elsewhere on the Moon (and perhaps elsewhere) are implanted. 3 The regolith layer, with its embedded historical record, is buried by a more recent lava flow, forming a palaeoregolith. The new lava flow may bake out some of the trapped volatiles and implanted solar wind from the palaeoregolith layer, though degassing and associated oxidization effects (similar to those processes described in Shearer et al. 2014; Joy et al. 2015; Treiman et al. 2016) will vary depending on the temperature of the new lava flow and thickness of the trapped regolith horizon (Fagents et al. 2010; Rumpf et al. 2013; Crawford et al. 2009). 4 The process begins again on the upper surface generating a younger surficial regolith. Modified from Crawford et al. (2007). This model could also be applicable for regolith units that are sandwiched between, or buried under, pyroclastic picritic glass bead deposits (McKay 2009) or buried under impact ejecta blankets (with the caveat that such ejecta emplacement may also contribute to a debris of ballistic sedimentation and mixing of the buried regolith layer) (McKay 2009) 
Identifying trapped palaeoregoliths will require using a variety of techniques to identify suitable stratigraphic horizons (Crawford et al. 2007). Such methods include: (1) ground penetrating radar techniques either from orbit (such as those made by the Kaguya spacecraft, e.g. Ono et al. 2009; Oshigami et al. 2009) or on rover deployed devices (such as that on the Change' 3 rover; Xiao et al. 2015; Fa et al. 2015); (2) high resolution images of layered bedrock exposure such as those available from the Apollo missions (Swann et al. 1972) or imaged remotely via high resolution images such as those collected by the Lunar Reconnaissance Orbiter Narrow Angle Camera (Crawford et al. 2009).

In some cases it may be possible to access palaeoregolith deposits in locations where nature has exposed the underlying stratigraphy (e.g. Crawford et al. 2009). For example, several layered sequences have been identified in the walls of impact craters (Fig. 6a, b: Ashley et al. 2012; Enns and Robinson 2013; Needham et al. 2013), and volcanic lava tube skylights (Fig. 6c, d: Ashley et al. 2012; Robinson et al. 2012) as potential targets for further study and exploration. However, these deposits tend to occur on steep angle slopes and would be challenging for future exploration efforts, and more accessible targets include large blocks of layered deposits that have been dislodged from high angle slopes collecting at the base of impact craters (Fig. 6e, f: Zanetti et al. 2011; Kickapoo Lunar Research Team and Kramer 2013). If suitable outcrops cannot be located, accessing these archives will then require deep drilling through overlying rock units (Crawford et al. 2007). Although challenging technologically, drilling would result in recovery of more pristine palaeoregolith samples than is likely to be possible from sampling outcrops at the surface.
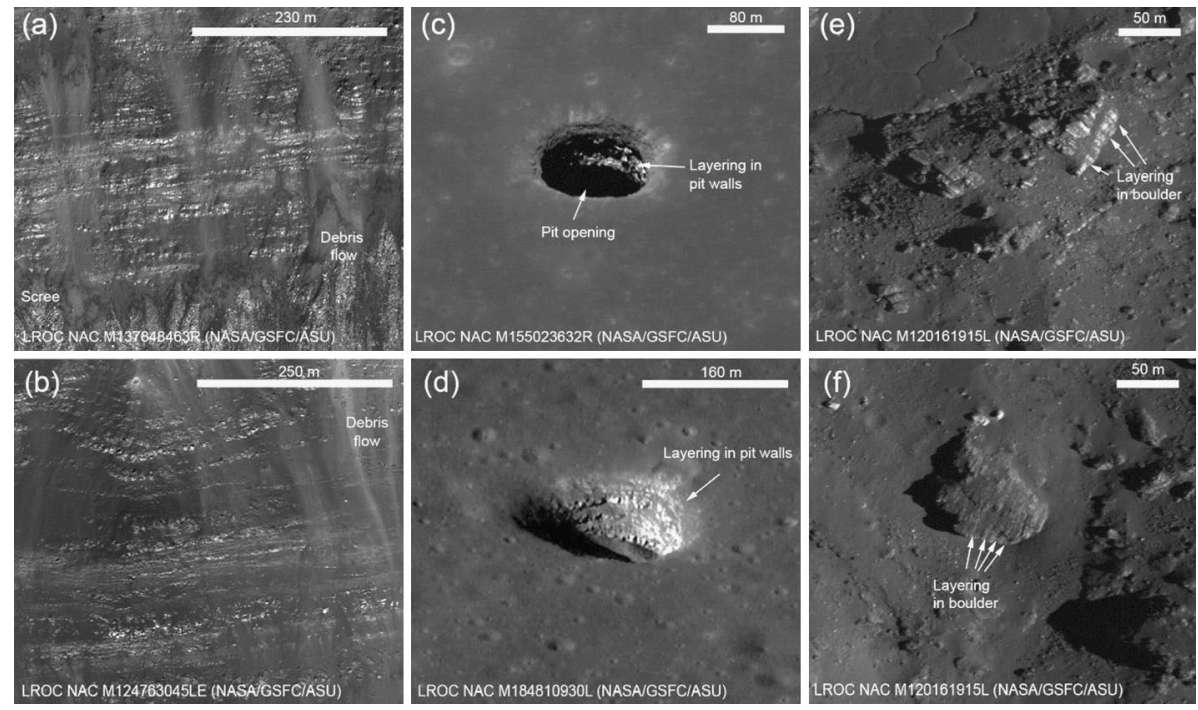

Fig. 6 Lunar Reconnaissance Orbiter high resolution (NAC) images of sites where palaeoregoliths may be accessible for exploration efforts at the lunar surface. a Exposed wall of Marias A impact crater located in Oceanus Procellarum, revealing layered basalts partially covered by debris flows. b Wall of Euler impact crater located in Mare Imbrium revealing layered basalts partially covered by debris flows. c Oblique LROC NAC view of lunar pits with layered walls found in Mare Tranquillitatis and $\mathbf{d}$ Mare Ingenii. e, f Boulders with layers (possibly discrete lava flows) found on the lunar surface within the crater Aristarchus. Scale bars in all cases have been estimated from pixel resolution of NAC image. Adapted from Fig. 19 of Crawford et al. (2014) 


\section{Summary}

The bombardment history of the inner Solar System is uniquely revealed on the Moon and this record is critical to aid our understanding of the evolution of the terrestrial planets, including the Earth (e.g. NRC 2007).

We have outlined here how the Moon potentially preserves an archive of the types of small bodies that have been migrating through the Solar System through time. Identification and characterisation of such bodies at different points in lunar history will help to reveal the nature of planetary migration and transfer of volatiles across the Solar System. Such information is critical for providing constraints for models of Solar System dynamical evolution, and relationship to exo-planetary systems.

A range of different samples are available to study different temporal archives. For example, partial melts of the lunar interior such as mare basalts provide insights to the amount and isotopic composition of impactors delivered during the earliest part of the Moon's history in a period of late accretion (Day and Walker 2015; Barnes et al. 2016). Samples of radiometrically dated impact melt breccias, which are linked to known crater or basin forming events, provide evidence of the highly siderophile element budget of ancient impactor species (e.g. Walker et al. 2015). Lunar regolith samples such as soils, drill cores and regolith breccias potentially host fragments of surviving projectile debris and characterisation of such material directly enables identification of parent body impactor type (e.g. Joy et al. 2012 and references therein). Future exploration efforts that sample and return to Earth lunar regolith samples will enable a global sampling of such extra-lunar material.

Acknowledgments Material in this review article has been brought together from work published previously by Crawford and Joy (2014), Crawford et al. (2007), Joy et al. (2011a, b, 2012, 2014), Joy (2014), and Fagan et al. (2014). We thank two anonymous reviewers for their helpful suggestions to improve the manuscript, and Dr. Gudipati for editorial handling. We acknowledge funding from various sources including Leverhulme Trust grants 2011-569 (PI Joy) and F/07 112/P (PI Crawford), STFC grant ST/ M001253/1 (Co-I Joy), Royal Society University Fellowship (PI Joy RS/UF140190), NASA Lunar Science Institute cooperative NNA09DB33A (PI Kring), Solar System Exploration Research Virtual Institute cooperative agreement NNA14AB07A (PI Kring). This is LPI publication number LPI-001978.

Open Access This article is distributed under the terms of the Creative Commons Attribution 4.0 International License (http://creativecommons.org/licenses/by/4.0/), which permits unrestricted use, distribution, and reproduction in any medium, provided you give appropriate credit to the original author(s) and the source, provide a link to the Creative Commons license, and indicate if changes were made.

\section{References}

J.C. Armstrong, Earth Moon Planets 107, 43-54 (2011)

J.C. Armstrong, L.E. Wells, G. Gonzalez, Icarus 160, 183-196 (2002)

N.A. Artemieva, V.V. Shuvalov, Sol. Syst. Res. 42, 329-334 (2008)

R. Arvidson, G. Crozaz, R.J. Drozd, C.M. Hohenberg, C.J. Morgan, The Moon 13, 259-276 (1975)

J. W. Ashley, Elements: an international magazine of mineralogy, geochemistry, and petrology. 11(1), 10 (2015)

J. W. Ashley, M. S. Robinson, A. K. Boyd, R. V. Wagner, E. J. Speyerer, B. R. Hawke, H. Hiesinger, C. H. van der Bogert, K. Burns, H. Sato, Lunar and Planetary Science XLIII, Abstract \#1659 (2012)

C. Avdellidou, M. C. Price, M. Delbo, P. Ioannidis, M. J. Cole, MNRAS 456 (3), 2957-2965. doi:10.1093/ mnras/stv2844 (2016)

J. J. Barnes, D. A. Kring,, R. Tartèse, I. A. Franchi,, M. Anand, S.S. Russell, Nature Commun. 7, doi:10. 1038/ncomms11684 (2016) 
A. Basu, D.D. Bogard, D.H. Garrison, H.V. Lauer, D. Lindstrom, D.S. McKay, R.V. Morris, C.M. Pieters, S.J. Wentworth, Lunar and Planetary Science XXXI, Abstract \#1941 (2000)

B.L. Beard, J.M. Ludois, T.J. Lapen, C.M. Johnson, Earth Planet. Sci. Lett. 361, 173-182 (2013)

W. R. Binns, M. H. Israel, E. R. Christian, A. C. Cummings, G. A. de Nolfo, K. A. Lave, R. A. Leske, R. A. Mewaldt, E. C. Stone, T. T. von Rosenvinge, M. E. Wiedenbeck, Science 342, 677-680. doi:10. 1126/science.aad6004 (2016)

N. J. F. Blamey, J. Parnell, S. McMahon, D. F. Mark, T. Tomkinson, M. Lee, J. Shivak, M. R. M. Izawa, N. R. Banerjee, R. L. Flemming, Nature Commun. 6, 7399. doi:10.1038/ncomms8399 (2015)

P. A. Bland, N. A. Artemieva, G. S. Collins, W. F. Bottke, D. B. J. Bussey, K. H. Joy, Lunar and Planetary Science XXXXIX, Abstract \#2045 (2008)

P.J. Blau, J.I. Goldstein, Geochim. Cosmochim. Acta 39, 305-306 (1975)

D. Bogard, W. Hirsch, in Proceedings of the 6th Lunar Science Conference (1975), p. 2057-2083

D. Bogard, L. Nyquist, in Proceedings of the 3rd Lunar Science Conference, p. 1797-1819

D. Bogard, L. Nyquist, in Proceedings of the 4th Lunar Science Conference, p. 1975-1986

D. Bogard, L. Nyquist, W. Hirsch, D. R. Moore, in Proceedings of the 4th Lunar Science Conference (1973), p. 79

D. Bogard, L. Nyquist, W. Hirsch, Abstracts of the 5th Lunar Science Conference (1974), p. 73-75

D. Bogard, R. Morris, P. Johnson, H. Lauer, J. Geophys. Res. Solid Earth 87, A221-A231 (1982)

R. Borchardt, D. Stoffler, B. Spettel, H. Palme, H. Wanke, J. Geophys. Res. 91, E43-E54 (1986)

W.F. Bottke, H.F. Levison, D. Nesvorný, L. Dones, Icarus 190, 203-223 (2007)

W.F. Bottke, R.J. Walker, J.M.D. Day, D. Nesvorny, L. Elkins-Tanton, Science 330, 1527-1530 (2010)

W. F. Bottke, D. Vokrouhlický, D. Minton, D. Nesvorný, A. Morbidelli, R. Brasser, B. Simonson, H. F. Levison, Nature 485, 78-81. doi:10.1038/nature10967 (2012)

J.W. Boyce, A. H. Treiman, Y. Guan, C. Ma, J. M. Eiler, J. Gross, J.P. Greenwood, E. M. Stolper, Sci. Adv. 1(8), e1500380. doi:10.1126/sciadv.1500380 (2015)

A. Brack, P. Baglioni, G. Borruat, F. Brandstätter, R. Demets, H.G.M. Edwards, M. Genge, G. Kurat, M.F. Miller, E.M. Newton, C.T. Pillinger, A. Roten, C.-E. Wäsch, Planet. Space Sci. 50, 763-772 (2002)

A. D. Brandon, M. Humayun, I. S. Puchtel, M. E. Zolensky, Geochim. Cosmochim. Acta 69, 1619-1631. doi:10.1016/j.gca.2004.10.005 (2005)

D. Breitschwerdt, J. Feige, M.M. Schulreich, M.A. de Avillez, C. Dettbarn, B. Fuchs, Nature 532, 73-76 (2016)

M.J. Burchell, S.A. Bowden, M. Cole, M.C. Price, J. Parnell, Astrobiology 14, 473-485 (2014)

M.J. Burchell, K.H. McDermott, M.C. Price, L.J. Yolland, Philos. Trans. R. Soc. A Math. Phys. Eng. Sci. 372. doi:10.1098/rsta.2013.0190 (2014b)

H. Busemann, A.N. Nguyen, G.D. Cody, P. Hoppe, A.D. Kilcoyne, R.M. Stroud, T.J. Zega, L.R. Nittler, Earth Planet. Sci. Lett. 288(1), 44-57 (2009)

J.T.S. Cahill, J.J. Hagerty, D.J. Lawrence, R.L. Klima, D.T. Blewett, Icarus 243, 27-30 (2014)

C. R. Chapman, Nature 419, 791-794. doi:10.1038/419791a (2002)

B.A. Cohen, T.D. Swindle, D.A. Kring, Science 290, 1754-1756 (2000)

I.A. Crawford, K.H. Joy, Philos. Trans. R. Soc. A372(20130315), 1-21 (2014)

I.A. Crawford, S.A. Fagents, K. H. Joy, Astronomy Geophys. 48, 3.18-3.21 (2007)

I.A. Crawford, E.C. Baldwin, E.A. Taylor, J.A. Bailey, K. Tsembelis, Astrobiology 8, $242-252$ (2008)

I.A. Crawford, K. H. Joy, S.A. Fagents, M. E. Rumpf, Lunar Reconnaissance Orbiter Science Targeting Meeting, held June 9-11, in Tempe, Arizona. LPI Contribution No. 1483, p. 29 (2009)

I.A. Crawford, K. H. Joy, S.A. Fagents, M. E.Rumpf, Earth Moon Planets 107, 75-85. doi:10.1007/s11038010-9358-z (2010)

I.A. Crawford, K. H. Joy, M. Anand, Chapter 25: Lunar Exploration. Encyclopaedia of the Solar System 3rd edition. (2014), p. 555-582

M. Ćuk, Icarus 218, 69-79 (2012)

M. Ćuk, B.J. Gladman, S.T. Stewart, Icarus 207, 590-594 (2010)

C.W. Dale, K.W. Burton, R.C. Greenwood, A. Gannoun, J. Wade, B.J. Wood, D.G. Pearson, Science 336, 72-75 (2012)

G.B. Dalrymple, G. Ryder, J. Geophys. Res. 98, 13085-13095 (1993)

G.B. Dalrymple, G. Ryder, J. Geophys. Res. 101, 26069-26084 (1996)

R. T. Daly, and P. H. Schultz, Icarus 264, 9-19, doi:10.1016/j.icarus.2015.08.034 (2016)

J.M.D. Day, R.J. Walker, Earth Planet. Sci. Lett. 423, 114-124 (2015)

J.M.D. Day, C. Floss, L.A. Taylor, M. Anand, A.D. Patchen, Geochim. Cosmochim. Acta 70, 5957-5989 (2006)

J.M.D. Day, R.J. Walker, L. Qin, D. Rumble III, Nature Geosci. 5, 614-617. doi:10.1038/ngeo1527 (2012) 
J.M.D. Day, A.D. Brandon, R. J. Walker, Rev. Mineral. Geochem. 81, 161-238. doi:10.2138/rmg.2016.81. 04 (2016)

P. Eberhardt, O. Eugster, J. Geiss, N. Grögler, S. Guggisberg, M. Mörgeli, in Proceedings of the 7th Lunar Science Conference (1976), p. 563-585

L.T. Elkins-Tanton, S. Burgess, Q.-Z. Yin, Earth Planet Sci. Lett. 304, 326-336 (2011)

A.C. Enns, M.S. Robinson, Lunar and Planetary Science XLIV, Abstract \#2751 (2013)

O. Eugster, M. Burger, U. Krähenbühl, T. Michel, J. Beer, H.J. Hofmann, H.A. Synal, W. Woelfli, R.C. Finkel, Geochim. Cosmochim. Acta 55, 3139-3148 (1991)

O. Eugster, D. Terribilini, E. Polnau, J. Kramers, Meteor. Planet. Sci. 36, 1097-1115 (2001)

W. Fa, Z.M.-H. Hu, T. Liu, J.B. Plescia, Geophys. Res. Lett. 42, 10179-10187 (2015)

A. L. Fagan, K. H. Joy, D. D. Bogard, D. A. Kring, Earth Moon Planets 112, 59-71. doi:10.1007/s11038014-9437-7 (2014)

A. L. Fagan, K. H. Joy, D. A. Kring, in Lunar and Planetary Science XLVI, Abstract \#1405 (2015)

A. L. Fagan, K. H. Joy, K. Nagashima, G.R. Huss, D. A. Kring, in Lunar and Planetary Science XLVI, Abstract \#2789 (2016)

S.A. Fagents, M.E. Rumpf, I.A. Crawford, K.H. Joy, Icarus 207, 595-604 (2010)

C.I. Fassett, J.W. Head, S.J. Kadish, E. Mazarico, G. A. Neumann, D.E. Smith, M.T. Zuber, J. Geophys. Res. 117, E00H06. doi:10.1029/2011JE003951 (2012)

V.A. Fernandes, J. Fritz, B.P. Weiss, I. Garrick-Bethell, D.L. Shuster, Meteorit. Planet. Sci. 48, 241-269 (2013)

M. Fischer-Gödde, H. Becker, Geochim. Cosmochim. Acta 77, 135-156 (2012)

M.J. Fitzgerald, J.B. Jones, Meteorit. Planet. Sci. 12, $443-458$ (1977)

L. Folco, M. Di Martino, A. El Barkooky, M. D’Orazio, A. Lethy, S. Urbini, I. Nicolosi, M. Hafez, C. Cordier, M. van Ginneken, A. Zeoli, A.M. Radwan, S. El Khrepy, M. El Gabry, M. Gomaa, A.A. Barakat, R. Serra, M. El Sharkawi, Geology 39, 179-182 (2011)

D.R. Frank, M.E. Zolensky, L. Le, Geochim. Cosmochim. Acta 142, 240-259 (2014)

H. Frey, Spec. Pap. Geol. Soc. Am. 477, 53-75. doi:10.1130/2011.2477(02) (2011)

M. Fries, Extralunar Materials in Lunar Regolith. A White Paper Submitted for the NRC Decadal Survey (2010)

M. Fries, A. Steele, Workshop on Science Associated with the Lunar Exploration Architecture (2007)

E. Füri, B. Marty, Nature Geosci. 8, 515-522. doi:10.1038/ngeo2451 (2015)

E. Füri, B. Marty, S.S. Assonov, Icarus 218, 220-229 (2012)

K.E. Gibson, G.W. Moore, Science 179, 69-71 (1973)

B. J. Gladman, J. Coffey, Meteorit. Planet. Sci. 44, 285-291. doi:10.1111/j.1945-5100.2009.tb00734.x (2009)

B.J. Gladman, J.A. Burns, M. Duncan, P. Lee, H.F. Levison, Science 271(5254), 1387-1392 (1996)

J. I. Goldstein, H. Yakowitz, Abstracts of the 2nd Lunar Science Conference (1971), p. 177

J. I. Goldstein, E. P. Henderson, H. Yakowitz, in Proceedings of the Apollo 11 Lunar Science Conference (1970), p. 499

J. I. Goldstein, H. J. Axon, S. O. Agrell, Earth Planet. Sci. Lett. 28, 217-224. doi:10.1016/0012$821 \mathrm{X}(75) 90231-9(1975)$

R.S. Gomes, H.F. Levison, A. Morbidelli, K. Tsiganis, Nature 435, 466-469 (2005)

J. Gross, 77th annual meeting of the meteoritical society, Abstract \#5381 (2014)

J. Gross, A. H. Treiman, Lunar and planetary science XLI, Abstract \#2180 (2010)

T.V. Gudkova, Ph. Lognonné, J. Gagnepain-Beyneix, Icarus 211, 1049-1065. doi:10.1016/j.icarus.2010.10. 028 (2011)

J. L. Gutiérrez, in Proceedings of the first European workshop on exo-astrobiology (2002), p. 187-191

H.P. Haack, P. Farinella, E.R.D. Scott, K. Keil, Icarus 119, 182-191 (1996)

S. E. Haggerty, in The Apollo 15 Lunar Samples, ed. by J. W. Chamberlain and C. Watkins (1972), p. 85-87

W.K. Hartmann, Icarus 13, 299-301 (1970)

W. K. Hartmann, G. Ryder, L. Dones, D.H. Grinspoon, in Origin of the Earth and Moon, ed. by R.M. Righter, R. Canup (Univ Arizona Press, Tucson, 2000), p. 493-512

K. Hashizume, M. Chaussidon, B. Marty, F. Robert, Science 290, 1142-1145 (2000)

K. Hashizume, B. Marty, R. Wieler, Earth Planet. Sci. Lett. 202, 201-216 (2002)

H. Hintenberger, H. Weber, in Proceedings of the 4th lunar and planetary science conference (1973), p. 2003-2019

H. Hintenberger, H. Weber, H.H. Voshage, H. Wänke, F. Begemann, F. Wlotzka, Geochim. Cosmochim. Acta Suppl. 1, 1269 (1970)

H. Hintenberger, H. Weber, L. Schultz, in Proceedings of the 5th Lunar Science Conference (1974), p. $2005-2022$ 
H. Hintenberger, L. Schultz, H. Weber, in Proceedings of the 6th Lunar Science Conference (1975), p. $2261-2270$

F. Hörz, R. Grieve, G. Heiken, P. Spudis, A. Binder, Lunar surface processes, in Lunar Sourcebook, ed. by G. Heiken, D. Vaniman, B.M. French (Cambridge University Press, Cambridge, 1991), pp. 1-12

R. M. Housley, R. W. Grant, M. Abdel-Gawad, in Proceedings of the Lunar 3rd Science Conference, vol. 3 (1972), p. 1065

H.A. Ishii, J.P. Bradley, Z.R. Dai, M. Chi, A.T. Kearsley, M.J. Burchell, N.D. Browning, F. Molster, Science 319(5862), 447-450 (2008)

B. C. Johnson, H. J. Melosh, Nature 485, 75-77. doi:10.1038/nature10982 (2012)

B.L. Jolliff, R.L. Korote, L.A. Haskin, Lunar and planetary science XXIV, Abstract \#729 (1993)

U.G. Jørgensen, P.W.U. Appel, Y. Hatsukawa, R. Frei, M. Oshima, Y. Toh, A. Kimura, Icarus 204, 368-380 (2009)

K. H. Joy, Temporal impact history of the Moon: RAS Winton Capital Prize talk. The Observatory: a review of astronomy (2014)

K. H. Joy, D. A. Kring, D. D. Bogard, D. S. McKay, M. E. Zolensky, Geochim. Cosmochim. Acta 75, 7208-7225. doi:10.1016/j.gca.2011.09.018 (2011a)

K. H. Joy, D. K. Ross, M. E. Zolensky, D. A. Kring, 2011 Annual Meeting of the Lunar Exploration Analysis Group, Abstract \#2007 (2011b)

K. H. Joy, M. E. Zolensky, K. Nagashima, G. R. Huss, D. S. McKay, D. K. Ross, D. A. Kring, Science 336, 1426-1429. doi 10.1126/science.1219633 (2012)

K. H. Joy, S. Messenger, M. E. Zolensky, D. R. Frank, D. A. Kring, 76th annual meeting of the meteoritical society, Abstract \#5315 (2013)

K. H. Joy, I. A. Crawford, G. Huss, K. Nagashima, G. J. Taylor, Meteorit. Planet. Sci. 49, 677-695. doi:10. 1111/maps.12270 (2014)

K. H. Joy, C. Visscher, M. E. Zolensky, T. Mikouchi, K. Hagiya, K. Ohsumi, D. A. Kring, Meteorit. Planet. Sci. 50, 1157-1172. doi:10.1111/maps.12462 (2015)

J. Karner, J.J. Papike, C.K. Shearer, Am. Mineral. 88, 806-816 (2003)

J. Karner, J.J. Papike, C.K. Shearer, Am. Mineral. 89, 1101-1109 (2004)

J. Karner, J. J. Papike, C. K. Shearer, Am. Mineral. 91, 1574-1582. doi:10.2138/am.2006.2103 1574 (2006)

C. Kato, F. Moynier, M. C. Valdes, J. K. Dhaliwal, J.M.D. Day, Nature Commun. 6, 7617. doi:10.1038/ ncomms8617 (2015)

Kickapoo Lunar Research Team, G. Kramer, Icarus 228, 141-148. doi:10.1016/j.icarus.2013.10.003 (2013)

T. Kirsten, J. Deubner, H. Ducati, W. Gentner, P. Horn, E. Jessberger, S. Kalbitzer, I. Kaneoka, J. Kiko, W. Kratschmer, H. W. Muller, T. Plieninger, S. K. Thio, Abstracts of the 3rd Lunar Science Conference (1972), p. 452-454

C. Koeberl, Earth Moon Planets 92, 79-87 (2003)

R.L. Korotev, Meteorit. Planet. Sci. 31, 403-412 (1996)

R.L. Korotev, B.L. Jolliff, R.A. Zeigler, J.J. Gillis, L.A. Haskin, Geochim. Cosmochim. Acta 67, 4895-4923 (2003)

D.A. Kring, Astrobiology 3, 133-152 (2003)

D. A. Kring, B. A. Cohen (2002) J. Geophys. Res. 107 (E2), 4-1-4-6. doi:10.1029/2001JE001529 (2002)

T. S. Kruijer, T. Kleine, M. Fischer-Gödde, P. Sprung, Nature 520, 534-537. doi:10.1038/nature 14360 (2015)

M. Le Feuvre, M.A. Wieczorek, Icarus 214, 1-20. doi:10.1016/j.icarus.2011.03.010 (2011)

H.F. Levison, W.F. Bottke, M. Gounelle, A. Morbidelli, D. Nesvorny, K. Tsiganis, Nature 460, 364-366 (2009)

Y. Liu, A. Zhang, L.A. Taylor, 72nd Annual Meteoritical Society Meeting, Abstract \#5434 (2009)

J. Liu, M. Sharp, R.D. Ash, D.A. Kring, R.J. Walker, Geochim. Cosmochim. Acta 155, 122-153 (2015)

S. Lorenzetti, H. Busemann, O. Eugster, Meteorit. Planet. Sci. 40, 315-327 (2005)

S. G. Love, K. Keil, Meteorit. Planet. Sci. 30, 269-278. doi:10.1111/j.1945-5100.1995.tb01125.x (1995)

P. Lucey, R.L. Korotev, J.J. Gillis, L.A. Taylor, D. Lawrence, B.A. Campbell, R. Elphic, B. Feldmann, L.L. Hood, D. Hunten, M. Mendillo, S. Noble, J. J. Papike, R.C. Reedy, S. Lawson, T. Prettyman, O. Gasault, S. Maurice, Understanding the lunar surface and Space-Moon interactions. in New Views of the Moon, ed. by B. L. Jolliff, M. A. Wieczorek, C. K. Shearer, and C. R. Neal, Rev. Mineral. Geochem. 60, 83-219 (2006)

E. E. Mamajek, S. A. Barenfeld, V. D. Ivanov, A. Y. Kniazev, P. Väisänen, Y. Beletsky, H. M. J. Boffin, Astrophys. J. Lett. 800, L17. doi:10.1088/2041-8205/800/1/L17 (2015)

S. Marchi, W.F. Bottke, D.A. Kring, A. Morbidelli, Earth Planet. Sci. Lett. 325-326, 27-38 (2012)

R. Matthewman, R. W. Court, I. A. Crawford, A. P. Jones, K. H. Joy, M. A. Sephton, Astrobiology 15, 154-168. doi:10.1089/ast.2014.1217 (2015) 
F. M. McCubbin, K. E. Vander Kaaden, R. Tartèse, R. L. Klima, Y. Liu, J. Mortimer, J. J. Barnes, C. K. Shearer, A. H. Treiman, D. J. Lawrence, S. M. Elardo, D. M. Hurley, J. W. Boyce, M. Anand, Am. Mineral. 100, 1668-1707. doi:10.2138/am-2015-4934 (2015)

D.S. McKay, Lunar Reconnaissance Orbiter Science Targeting Meeting, Abstract \#6014 (2009)

D.S. McKay, J.L. Carter, W.R. Greenwood, Science 171, 479-480 (1970)

D.S. McKay, D. D. Bogard, R. V. Morris, R. L. Korotev, P. Johnson, S. J. Wentworth, in Proceedings of the 16th Lunar and Planetary Science Conference. J. Geophys. Res. 91, D277-D303 (1986)

D.S. McKay, D. D. Bogard, R. V. Morris, R. L. Korotev, P. Johnson, S. J. Wentworth, P. Johnson, in Proceedings of the 19th Lunar and Planetary Science Conference (1989), p. 19-41

D.S. McKay, G.Heiken, A. Basu G. Blanford, S. Simon, R. Reedy, B. M. French, J. J. Papike, The Lunar Regolith. in Lunar sourcebook, ed. by G. Heiken, D. Vaniman, B.M. French (Cambridge University Press, Cambridge, 1991), p. 286-356

K.D. McKeegan, J. Aléon, J. Bradley, D. Brownlee, H. Busemann, A. Butterworth, M. Chaussidon, S. Fallon, C. Floss, J. Gilmour, M. Gounelle et al., Science 314(5806), 1724-1728 (2006)

H.Y. McSween Jr., Earth Planet. Sci. Lett. 31, 193-199 (1976)

Meteoritical Bulletin database: The Meteoritical Society. (2016) http://www.lpi.usra.edu/meteor/

D.A. Minton, R. Malhotra, Nature 457, 1109-1111 (2009)

D.A. Minton, R. Malhotra, Icarus 207, 744-757 (2010)

A. Morbidelli, H.F. Levison, K. Tsiganis, R. Gomes, Nature 435, 462-465 (2005)

A. Morbidelli, S. Marchi, W.F. Bottke, D.A. Kring, Earth Planet. Sci. Lett. 355, 144-151. doi:10.1016/j.epsl. 2012.07.037 (2012)

J.W. Morgan, R. Ganapathy, J.C. Laul, E. Anders, Geochim. Cosmochim. Acta 37, 141-154 (1978)

R.V. Morris, in Proceedings of the 7th lunar and planetary science conference (1976), p. 315-335

R.V. Morris, in Proceedings of the 9th lunar and planetary science conference (1978), p. 2287-2297

R. V. Morris, W. A. Gose, in Proceedings of the 8th lunar and planetary science Conference (1977), p. $3113-3122$

R. V. Morris, H. Lauer Jr, W. A. Gose, in Proceedings of the 10th lunar and planetary science conference (1979), p. 1141-1157

R. V. Morris, R. Score, C. Dardano, G. Heiken, Handbook of Lunar Soils. NASA Planetary Materials Branch Publication, vol. 67 (1983)

R. V. Morris, T. Horz, F. J. Hörz, Geophys. Res. 91, E21-E42 (1986)

R.V. Morris, G. Klingelhöfer, R.L. Korotev, T.D. Shelfer, Hyperfine Interact. 117, 405-432 (1998)

H. Nagaoka, S. Takasawa, A.M. Nakamura, K. Sange, Meteorit. Planet. Sci. 49, 69-79 (2014)

D. Nakashima, T. Ushikubo, D.J. Joswiak, D.E. Brownlee, G. Matrajt, M.K. Weisberg, M.E. Zolensky, N.T. Kita, Earth Planet. Sci. Lett. 357-358, 355-365 (2012)

H. Needham, M. Rumpf, S. Fagents, American geophysical union fall meeting 2013, abstract \#V53C-2804 (2013)

G. Neukum, B. Ivanov, W. K. Hartmann, in Chronology and evolution of mars, ed. by R. Kallenbach, J. Geiss, W.K. Hartmann (Kluwer, Dordrecht, 2001), p. 55-86

G. A. Neumann, M. T Zuber, M. A. Wieczorek, J. W. Head, D. M. H. Baker, S. C. Solomon, D. E. Smith, F. G. Lemoine, E. Mazarico, T. J. Sabaka, S. J. Goossens, H. J. Melosh, R. J. Phillips, S. W. Asmar, A. S. Konopliv, J. G. Williams, M. M. Sori, J. M. Soderblom, K. Miljković, J. C. Andrews-Hanna, F. W. S. Nimmo, W. Kiefer, Sci. Adv. 1, e1500852. doi:10.1126/sciadv.1500852 (2015)

L.R. Nittler, R.D. Starr, S.Z. Weider, T.J. McCoy, W.V. Boynton, D.S. Ebel, C.M. Ernst, L.G. Evans, J.O. Goldsten, D.K. Hamara, D.J. Lawrence, R.L. McNutt Jr., ChE Schlemm, S.C. Solomon, A.L. Sprague, Science 333, 1847-1850 (2011)

M. D. Norman, Elements 5(1), 23-28. doi:10.2113/gselements.5.1.23 (2009)

M.D. Norman, A.A. Nemchin, Earth Planet. Sci. Lett. 388, 387-398 (2014)

M.D. Norman, R.A. Duncan, J.J. Huard, Geochim. Cosmochim. Acta 70, 6032-6049 (2006)

NRC (2007) (National Research Council). Report on the Scientific Context for the Exploration of the Moon. Committee on the Scientific Context for Exploration of the Moon Space Studies Board Division on Engineering and Physical Sciences. The National Academies Press, Washington. ISBN:0-309-109205, p. 120. (2007)

J. Oberst, Y. Nakamura, Icarus, 91(2), 315-325. doi.10.1016/0019-1035(91)90027 (1991)

J. Oberst, A. Christou, R. Suggs, D. Moser, I.J. Daubar, A.S. McEwen, M. Burchell, T. Kawamura, H. Hiesingeri, K. Wünnemann, R. Wagner, M.S. Robinson, Planet. Space Sci. 74(1), 179-193 (2012)

L. Ong, E.I. Asphaug, D.R. Korycansky, F. Coker, Icarus 207, 578-589 (2010)

T. Ono, A.Kumamoto, H. Nakagawa, Y. Yamaguchi, S. Oshigami, A. Yamaji, T. Kobayashi, Y. Kasahara, H. Oya, Science 323, 909-912. doi:10.1126/science.1165988 (2009) 
S. Oshigami, S. Y. Yamaguchi, A. Yamaji, T. Ono, A. Kumamoto, T. Kobayashi, H. Nakagawa, Geophys. Res. Lett. 36, L18202. doi:10.1029/2009GL039835 (2009)

J. J. Papike, L. Taylor, S. Simon, Lunar Minerals. in Lunar Sourcebook: A User's Guide to the Moon, ed. by Grant H. Heiken, D. Vaniman, B.M. French. (Cambridge University Press, Cambridge, 1991). ISBN 0-521-33444-6

J.J. Papike, J.M. Karner, C.K. Shearer, Am. Mineral. 88, 469-472 (2003)

R. Pepin, L. Nyquist, D. Phinney, D. Black, Geochim. Cosmochim. Acta. Suppl. 1, 1435 (1970)

R. Pepin, J. Basford, J. Dragon, M. Coscio Jr, V. Murthy, in Proceedings of the 5th Lunar Science Conference (1974), p. 2149-2184

P.N. Peplowski, D.J. Lawrence, W.C. Feldman, J.O. Goldsten, D. Bazell, L.G. Evans, J.W. Head, L.R. Nittler, S.C. Solomon, S.Z. Weider, Icarus 253, 346-363 (2015)

J. R. Pernet-Fisher, K. H. Joy, Astronomy Geophys. 57(1), 1.26-1.30. doi:10.1093/astrogeo/atw039 (2016)

E. Pierazzo, H.J. Melosh, Annu. Rev. Earth Planet. Sci. 28, 141-167 (2000)

I.S. Puchtel, R.J. Walker, O.B. James, D.A. Kring, Geochim. Cosmochim. Acta 72, 3022-3042 (2008)

W. Quaide, T. Bunch, Geochim. Cosmochim. Acta. Suppl., Vol. 1. Proceedings of the Apollo 11 Lunar Science Conference (1970), p. 711-729

M.R. Rampino (2015) MNRAS 448, 1816-1820 doi:10.1093/mnras/stu2708 (2015)

F.J. Rietmeijer, Planet. Mater. Rev. Mineral. 36, 1-2 (1998)

M.S. Robinson, J.W. Ashley, A.K. Boyd, R.V. Wagner, E.J. Speyerer, B.R. Hawke, H. Hiesinger, C.H. van der Bogert, Planet. Space Sci. 69(1), 18-27 (2012)

M. S. Robinson, A. K. Boyd, B.W. Denevi, S.J. Lawrence, A. S. McEwen, D. E. Moser, R. Z. Povilaitis, R.W. Stelling, R. M. Suggs, S. D. Thompson, R. V. Wagner, Icarus 252, 229-235. doi:10.1016/j.icarus. 2015.01.019 (2015)

D. C. Rubie, V. Laurenz, S. A. Jacobson1, A. Morbidelli, H. Palme, A. K. Vogel, D. J. Frost, Lunar and Planetary Science XLVII, Abstract \#1112 (2016)

A.E. Rubin, Meteorit. Planet. Sci. 32, 135-141 (1997)

M.E. Rumpf, S.A. Fagents, I.A. Crawford, K.H. Joy (2013) J. Geophys. Res. 118, 382-397. doi:10.1029/ 2012JE004131 (2013)

G. Ryder, Astrobiology 3, 3-6 (2003)

G. Ryder, E.O.S. Trans, Am. Geophys. Un. 71, 313-323 (1990)

G. Ryder, C. Koeberl, S.J. Mojzsi, in Origin of the Earth and Moon ed. by R. Canup, K. Righter (University of Arizona Press, Tucson, 2000), p. 475-492

P. H. Schultz, D. A. Crawford, Nature 535, 391-394. doi:10.1038/nature18278 (2016)

T.H. See, F. Hörz, R.V. Morris, J. Geophys. Res. 91, E3-E20 (1986)

M. Sharp, I. Gerasimenko, L. Loudin, J. Liu, O.B. James, I.S. Puchtel, R.J. Walker, Geochim. Cosmochim. Acta. 139131, 62-80 (2014)

C. K. Shearer, Z. D. Sharp, P. V. Burger, F. M. McCubbin, P. P. Provencio, A. J. Brearley, A. Steele, Geochim. Cosmochim. Acta. 139, 411-433. doi:10.1016/j.gca.2014.04.029 (2014)

J.F. Snape, A.A. Nemchin, M.L. Grange, J.J. Bellucci, F. Thiessen, M.J. Whitehouse, Geochim. Cosmochim. Acta 174, 13-29 (2016)

J.G. Spray, Ann. Rev. Earth Planet. Sci. 44, 139-174 (2016)

P. D. Spudis, G. J. Taylor, Lunar and Planetary Science XL, abstract 1039 (2009)

A. Steele, F. M. McCubbin, M. Fries, M. Glamoclija, L. Kater, H. Nekvasil, Science 329, 51. doi:10.1126/ science.1190541 (2010)

K.R. Stockstill-Cahill, T.J. McCoy, L.R. Nittler, S.Z. Weider, S.A. Hauck II, J. Geophys. Res. 117, E00L15 (2012)

J. Stodolna, D. Jacob, H. Leroux, Geochim. Cosmochim. Acta 87, 35-50 (2012)

D. Stöffler, G. Ryder, B.A. Ivanov, N.A. Artemieva, M.J. Cintala, R.A.F. Grieve, Cratering history and lunar chronology. in New Views of the Moon, eds. B. L. Jolliff, M. A. Wieczorek, C. K. Shearer, C. R. Neal. Rev. Mineral. Geochem. 60, 519-596 (2006)

D. Storzer, G.A. Wagner, Meteoritics 12, 368-369 (1977)

R.G. Strom, R. Malhotra, T. Ito, F. Yoshida, D.A. Kring, Science 309, 1847-1850 (2005)

C. Suavet, B. P. Weiss, W. S. Cassata, D. L. Shuster, J. Gattacceca, L. Chan, I. Garrick-Bethell, J. W. Head, T. L. Grove, M. D. Fuller, PNAS. doi/10.1073/pnas.1300341110 (2013)

R.M. Suggs, D.E. Moser, W.J. Cooke, R.J. Suggs, Icarus 238, 23-36 (2014)

V.V. Svetsov, V.V. Shuvalov, Planet. Space Sci. 117, 444-452 (2015)

G. Swann, N.G. Bailey, R.M. Batson, V.L. Freeman, M.H. Hait, J.W. Head, H.E. Holt, K.A. Howard, J.B. Irwin, K.B. Larson,W.R. Muehlberger, V.S. Reed, J.J. Rennilson, G.G. Schaber, D.R. Scott, L.T. Silver, R.L. Sutton, G.E. Ulrich, H.G. Wilshire, E.W. Wolfe, Preliminary geologic investigation of the Apollo 15 landing site, in Apollo 15 Preliminary Science Report. NASA (1972) 
R. Tartèse, Encyclopedia of Lunar Science, p. 1-10. doi:10.1007/978-3-319-05546-6_26-1 (2016)

F. Tera, D.A. Papanastassiou, G.J. Wasserburg, Earth Planet. Sci. Lett. 22, 1-21 (1974)

K. L. Thomas-Keprta, S. J. Clemett, S. Messenger, D. K. Ross, L. Le, Z. Rahman, D. S. McKay, E. K. Gibson Jr., C. Gonzalez, W. Peabody, Geochim. Cosmochim. Acta 134, 1-15. doi:10.1016/j.gca. 2014.02.047 (2014)

A.H. Treiman, J.W. Boyce, J. P. Greenwood, J. M. Eiler, J. Gross, Y. Guan, C. Ma, E. M. Stolper, Am. Mineral. doi:10.2138/am-2016-5582 (2016)

M. Trieloff, 78th Annual Meeting of the Meteoritical Society, Abstract \#5261 (2015)

K. Tsiganis, R.S. Gomes, A. Morbidelli, H.F. Levison, Nature 435, 459-461 (2005)

G. Turner, in Proceedings of the 10th Lunar and Planetary Science Conference 2, (1979), p. 1917-1941

G. Turner, P.H. Cadogan, C.J. Yonge, in Proceedings of the 4th Lunar Science Conference (1973), p. 1889-1914

T. Usui, C.M.O'.D. Alexander, J. Wang, J.I. Simon, J.H. Jones, T. Usui, Earth Planet. Sci. Lett. 410, 140-151 (2015)

W. M. Vaughan, J. W. Head, Lunar and Planetary Science XLV, Abstract \#2013 (2014)

J. C. G. Walker, C. Klein, M. Schidlowski, J. W. Schopf, D. J. Stevenson, M. R. Walter, Environmental Evolution of the Archean-Early Proterozoic Earth. Earth's Earliest Biosphere: Its Origin and Evolution, ed. by. Schopf J.W. (Princeton Univ Press, Princeton, 1983), p. 260-290

R.J. Walker, K. Bermingham, J. Liu, I.S. Puchtel, M. Touboul, E.A. Worsham, Chem. Geol. 411, 125-142 (2015)

A. Wallner, J. Feige, N. Kinoshita, M. Paul, L.K. Fifield, R. Golser, M. Honda, U. Linnemann, H. Matsuzaki, S. Merchel, G. Rugel, S.G. Tims, P. Steier, T. Yamagata, S.R. Winkler, Nature 532, 69-72 (2016)

J. Walton, S. Lakatos, D. Heymann, in Proceedings of the 4th Lunar and Planetary Science Conference (1973), p. 2079

H. Wänke, G. Dreibus, H. Palme, in Proceedings of the 7th Lunar Science Conference (1978), p. 83-110

P. H. Warren, J. T. Wasson, The compositional-petrographic search for pristine nonmare rocks: Third foray, in Proceedings of the 10th Lunar and Planetary Science Conference (1979), p. 583-610

H.W. Weber, L. Schultz, Abstracts of the 9th Lunar and Planetary Science Conference (1978), p. $1234-1236$

I. Weber, A. Morlok, A. Bischoff, D. Ward, H. Hiesinger, K. H. Joy, S. A. Crowther, H. Barden, N. D. Jastrzebski, J. D. Gilmour, R. A. Wogelius, R. C. Greenwood, I. A. Franchi, C. Münker, Meteorit. Planet. Sci. 51, 3-30. doi:10.1111/maps.12586 (2016)

S.Z. Weider, L.R. Nittler, R.D. Starr, T.J. McCoy, K.R. Stockstill-Cahill, P.K. Byrne, B.W. Denevi, J.W. Head, S.C. Solomon, J. Geophys. Res. 117, E00L05 (2012)

S.Z. Weider, L.R. Nittler, R.D. Starr, T.J. McCoy, S. Solomon, Icarus 235, 170-186 (2014)

G. W. Wetherill, in Proceedings of the 6th Lunar and Planetary Science Conference, vol. 2 (1975), p. $1539-1561$

M. A. Wieczorek, B. P. Weiss, S. T. Stewart, Science 335, 1212-1215. doi:10.1126/science.1214773 (2012)

R. Wieler (2016) Chemie der Erde. doi:10.1016/j.chemer.2016.06.001 (2016)

D.E. Wilhelms, J.F. McCauley, N. J. Trask, The Geologic History of the Moon. US Geological Survey Professional Paper 1348. Unites States Geological Survey, Dept. of the Interior, Washington D.C. (1987)

A. Wittmann, R. L. Korotev, Lunar and Planetary Science XLIV, Abstract \#3035 (2013)

S.F. Wolf, M.-S. Wang, M.E. Lipschutz, Meteorit. Planet. Sci. 44, 891-903 (2009)

J.A. Wood, U.B. Marvin, B.N. Powell, J.S. Dickey, Smithson. Astrophys. Obs. Spec. Rep. 307 (1970)

J.A. Wood, U. B. Marvin, J. B. Reed, G. J. Taylor, J. F. Bower, B. N. Powell, J.S. Dickey, Mineralogy and petrology of the Apollo 12 lunar sample. Smithsonian Astrophys. Obs. Spec. Rep. 333, 177 (1971)

L. Xiao, P. Zhu, G. Fang, Z. Xiao, Y. Zou, J. Zhao, N. Zhao, Y. Yuan, L. Qiao, X. Zhang, H. Zhang, Science 347(6227), 1226-1229 (2015)

E.D. Young, I.E. Kohl, P.H. Warren, D.C. Rubie, S.A. Jacobson, A. Morbidelli, Science 351 (6272), 493-496. doi:10.1126/science.aad0525 (2016)

Z. Yue, B.C. Johnson, D.A. Minton, H.J. Melosh, K. Di, W. Hu, Y. Liu, Nature Geosci. 6, 435-437. doi:10. 1038/ngeo1828 (2013)

M. Zanetti, H. Hiesinger, C.H. van der Bogert, B.L. Jolliff, Lunar Planet. Sci. 42, abstract \#2262 (2011)

V.N. Zharkov, Solar Syst. Res. 34, 1-11 (2000)

M.E. Zolensky, Meteorit. Planet. Sci. 32, 15-18 (1997)

M.E. Zolensky, M.K. Weisberg, P.C. Buchanan, D.W. Mittlefehldt, Meteorit. Planet. Sci. 31, 518-537 (1996) 
M.E. Zolensky, T.J. Zega, H. Yano, S. Wirick, A.J. Westphal, M.K. Weisberg, I. Weber, J.L. Warren, M.A. Velbel, A. Tsuchiyama, P. Tsou et al., Science 314(5806), 1735-1739 (2006)

M.E. Zolensky, K. Nakamura-Messenger, F. Rietmeijer, H. Leroux, T. Mikouchi, K. Ohsumi, S. Simon, L. Grossman, T. Stephan, M. Weisberg, M. Velbel, T. Zega, R. Stroud, K. Tomeoka, I. Ohnishi, N. Tomioka, T. Nakamura, G. Matrajt, D. Joswiak, D. Brownlee, F. Langenhorst, A. Krot, A. Kearsley, H. Ishii, G. Graham, Z.R. Dai, M. Chi, J. Bradley, K. Hagiya, M. Gounelle, J. Bridges, Meteorit. Planet. Sci. 43, 261-272 (2008) 